\title{
Identification and Functional Analysis of Two Purple Acid Phosphatases AtPAP17 and AtPAP26 Involved in Salt Tolerance in Arabidopsis thaliana Plant
}

\section{OPEN ACCESS}

Edited by:

Loredana F. Ciarmiello, University of Campania Luigi Vanvitelli,

Reviewed by:

Hayssam M. Ali,

King Saud University, Saudi Arabia

Mohammad Abass Ahanger,

Northwest A\&F University, China

*Correspondence:

Mohammad Sadegh Sabet ms.sabet@modares.ac.ir

Specialty section: This article was submitted to

Plant Abiotic Stress,

a section of the journal

Frontiers in Plant Science

Received: 18 October 2020 Accepted: 31 December 2020 Published: 15 February 2021

Citation:

Abbasi-Vineh MA, Sabet MS and Karimzadeh G (2021) Identification and Functional Analysis of Two Purple Acid Phosphatases AtPAP17 and AtPAP26 Involved in Salt

Tolerance in Arabidopsis thaliana Plant. Front. Plant Sci. 11:618716. doi: 10.3389/fp/s.2020.618716

\author{
Mohammad Ali Abbasi-Vineh", Mohammad Sadegh Sabet ${ }^{2 *}$ and Ghasem Karimzadeh² \\ 'Department of Agricultural Biotechnology, Faculty of Agriculture, Tarbiat Modares University, Tehran, Iran, ${ }^{2}$ Department \\ of Plant Genetics and Breeding, Faculty of Agriculture, Tarbiat Modares University, Tehran, Iran
}

Tolerance to salinity is a complex genetic trait including numerous physiological processes, such as metabolic pathways and gene networks; thereby, identification of genes indirectly affecting, as well as those directly influencing, is of utmost importance. In this study, we identified and elucidated the functional characterization of AtPAP17 and AtPAP26 genes, as two novel purple acid phosphatases associated with highsalt tolerance in $\mathrm{NaCl}$-stressed conditions. Here, the overexpression of both genes enhanced the expression level of AtSOS1, AtSOS2, AtSOS3, AtHKT1, AtVPV1, and AtNHX1 genes, involving in the $\mathrm{K}^{+} / \mathrm{Na}^{+}$homeostasis pathway. The improved expression of the genes led to facilitating intracellular $\mathrm{Na}^{+}$homeostasis and decreasing the ionspecific damages occurred in overexpressed genotypes (OEs). An increase in potassium content and $\mathrm{K}^{+} / \mathrm{Na}^{+}$ratio was observed in OE17 and OE26 genotypes as well; however, lower content of sodium accumulated in these plants at $150 \mathrm{mM} \mathrm{NaCl}$. The overexpression of these two genes resulted in the upregulation of the activity of the catalase, guaiacol peroxidase, and ascorbate peroxidase. Consequently, the overexpressed plants showed the lower levels of hydrogen peroxide where the lowest amount of lipid peroxidation occurred in these lines. Besides the oxidation resistance, the boost of the osmotic regulation through the increased proline and glycine-betaine coupled with a higher content of pigments and carbohydrates resulted in significantly enhancing biomass production and yield in the OEs under $150 \mathrm{mM} \mathrm{NaCl}$. High-salt stress was also responsible for a sharp induction on the expression of both PAP17 and PAP26 genes. Our results support the hypothesis that these two phosphatases are involved in plant responses to salt stress by APase activity and/or non-APase activity thereof. The overexpression of PAP17 and PAP26 could result in increasing the intracellular APase activity in both OEs, which exhibited significant increases in the total phosphate and free Pi content compared to the wild-type plants. Opposite results witnessed in mutant genotypes (Mu17, Mu26, and DM), associating with the loss of AtPAP17 and AtPAP26 functions, clearly confirmed the role of these two genes in salt tolerance. Hence, these genes can be used as candidate genes in molecular breeding approaches to improve the salinity tolerance of crop plants.

Keywords: gene expression profiling, SOS pathway, antioxidant activities, overexpressed and mutant plants, APase activity, Pi homeostasis 


\section{INTRODUCTION}

Salinity is one of the major abiotic factors affecting the growth, development, and productivity of agricultural crops (Munns and Gilliham, 2015; Parihar et al., 2015; Zörb et al., 2019). All main processes such as protein synthesis, photosynthesis, and metabolism of lipid and energy are adversely affected by salinity within plants (Woodrow et al., 2017; Zörb et al., 2019). Local salinity may be due to high levels of $\mathrm{Cl}^{-}, \mathrm{SO}_{4}{ }^{2-}, \mathrm{CO}_{3}{ }^{2-}, \mathrm{HCO}_{3}$, $\mathrm{Na}^{+}, \mathrm{K}^{+}, \mathrm{Mg}^{+}$, or $\mathrm{Ca}^{2+}$, but for many plants, $\mathrm{Na}^{+}$and $\mathrm{Cl}^{-}$ are the primary cause of ion-specific damage (Hasegawa, 2013). Salt stress causes alterations in plant metabolism, including ionic toxicity, reduction in water potential, and ion imbalances that reduce the uptake of nitrogen, potassium, and phosphorus (Brown et al., 2006; Munns and Tester, 2008; Bargaz et al., 2016; Annunziata et al., 2017). Some studies show that salinity causes phosphorus deficiencies or imbalances in plant cells, and the phosphate deprivation adversely impacts photosynthetic processes (Plaxton and Carswell, 1999; Hammond and White, 2008; Carstensen et al., 2018). Meanwhile, phosphorus plays an important role in plant's developmental processes at both cellular and whole plant level comprising respiration, photosynthesis, energy metabolism, membrane biosynthesis, regulation of several enzymes involved in protein synthesis, biosynthesis of nucleic acids, signaling pathways, and ion transport (Plaxton, 2004; Tran et al., 2010a; Malhotra et al., 2018).

The application of phosphate fertilizers, at first glance, can lead to improve salt tolerance in plants, which carried out, for example, in bean (Bargaz et al., 2016), eggplant (Elwan, 2010), and spinach (Kaya et al., 2001). By using this approach, the adverse effects of high salinity were alleviated on plant growth. The fact is, however, that the response of plants to the fertilizers depends on various factors such as fertilizer application method, nutrient source, cultivar as well as salt-stress severity (Machado and Serralheiro, 2017). In other words, the optimal fertilizer application rate is a challenging recommendation under salinity (Hatam et al., 2019, 2020). By way of illustration, in plants, such as Pistacia vera, supplied with higher concentrations of phosphate, the further phosphate accumulated with toxic effects in tissues of plants could lead to a drop in growth and whole productivity (Shahriaripour et al., 2011). Thus, just a moderate phosphate supply is required to boost salinity tolerance and, more importantly, providing such a precise amount of this nutrient would be problematic for each plant. The strategy used in the supplementary of inorganic fertilizers, most notably, may exacerbate soil salinization, and it is also primarily based on competition between ions; in fact, one ion limits the uptake of another ion (Machado and Serralheiro, 2017; Hatam et al., 2019, 2020). Therefore, we believe plant responses should be very efficient to $\mathrm{P}$ deficiency in the salinity-treated cells and accordingly regulate their development and growth.

An alternative approach is that plants themselves develop various adaptation strategies to cope with phosphate deficiency such as further releasing, recycling, and scavenging of inorganic phosphate (Pi) from internal and/or external resources (Goldstein et al., 1988; Duff et al., 1994; Del Pozo et al., 1999). The hydrolysis of the phosphate from a wide variety of anhydrides and phosphate esters is catalyzed by purple acid phosphatases (PAPs), a group of acid phosphatases (APase), in plants (Veljanovski et al., 2006; Plaxton and Tran, 2011).

However, a thorough understanding of the physiological functions of different classes of PAPs has not been accomplished in various conditions (Liao et al., 2003). The PAP family comprises 29 members in Arabidopsis thaliana (AtPAPs) genome, among which AtPAP17 and AtPAP26 play a critical role in the mobilization and utilization of intracellular or extracellular Pi (Wang et al., 2011, 2014; Robinson et al., 2012; Farhadi et al., 2020). Interestingly, AtPAP17 (AtACP5) is not only induced by $\mathrm{Pi}$ deprivation but also its expression level is increased by high salt stress and oxidative stress (Del Pozo et al., 1999). When Arabidopsis plants were exposed to salt, nitrogen starvation, cold, Pi deprivation, and sulfur starvation, the expression level of AtPAP26 gene is only induced by no-Pi and salt treatments (Lohrasebi et al., 2007).

Furthermore, the expression patterns of these genes with phosphatase and peroxidase activities in different environmental conditions support the hypothetical multifunctional activities of these two PAP enzymes (Del Pozo et al., 1999; Veljanovski et al., 2006). PP2A phosphatases, for more example, play a critical role in the regulatory reactive oxygen species (ROS) signaling networks in plants, which control metabolic changes, and contribute to transcriptional and post-translational regulation of antioxidant enzymes and pro-oxidant (Rahikainen et al., 2016). Therefore, it is proposed that AtPAP17 and AtPAP26 genes could play a role in the signaling of activities of ROS scavenging enzymes in salt-stress conditions.

Consequently, since nearly all cellular activities in eukaryotes are modulated by reversible phosphorylation, phosphatase functions embrace the whole range of cellular and developmental processes under various conditions (Luan, 1998; DeLong, 2006; Singh et al., 2010). In fact, several studies revealed that genes encoding protein phosphatases are critical components in signaling pathways responsible for ion-channel regulation in guard cells, abscisic acid (ABA) functions, vacuolar channel management, developmental processes, light-responsive transcription, regulation of abiotic stress responses, and so on (Sopory and Munshi, 1998; Luan, 2003; Schweighofer et al., 2004; DeLong, 2006; Singh et al., 2010). Therefore, AtPAP17 and AtPAP26 genes with APase activity genes and non-APase activity involved in adaptation responses more likely to take responsibility under salinity stress conditions.

The ultimate aim of this salinity tolerance research was to boost the ability of plants to reduce the negative influence of the stress in saline environments, to maintain growth and productivity. Having ensured about effects of AtPAP17 and AtPAP26 genes in response to salt stress, followed by understanding how these multifunctional genes respond to salt stress could help us to develop a better strategy for improving salt stress tolerance in crop plants. For this purpose, we evaluated the molecular, physiological, biochemical, and morphological effects of the overexpression and knockout mutation of AtPAP17 and AtPAP26 genes in transgenic and mutant plants on $\mathrm{Na}^{+}$ management compare to the wild-type ones. 


\section{MATERIALS AND METHODS}

\section{Plant Materials and Culture Conditions}

Besides A. thaliana ecotype Columbia-0 (Col-0), as wild-type plants, five other genotypes were used for all experiments in the current study: lines of atpap17 mutant (Mu17), atpap26 mutant (Mu26), atpap17/26 double mutant (DM), AtPAP17 overexpressing (OE17), and AtPAP26 overexpressing (OE26) (Farhadi et al., 2020).

Seeds were surface sterilized and stratified for $48 \mathrm{~h}$ at $4^{\circ} \mathrm{C}$, and pre-germinated on solid MS medium, $\mathrm{pH} 5.8$, containing $1 \%$ sucrose, and $0.7 \%$ agar for 11 days. Before exposing to the treatments, 11-day old seedlings were transferred into $15 \mathrm{ml}$ of half-strength liquid MS medium supplemented with $1.25 \mathrm{mM} \mathrm{KH}_{2} \mathrm{PO}_{4}$. All samples were incubated for 3 days on an orbital shaker at $90 \mathrm{rpm}$ to achieve identical nutritional states. Subsequently, the 14-day old seedlings were subjected to 0, 50, 100 , and $150 \mathrm{mM} \mathrm{NaCl}$ on half-strength liquid MS medium for 12 days. The culture medium was refreshed every $72 \mathrm{~h}$ for each sample. All genotypes were grown at $25^{\circ} \mathrm{C}$ under fluorescent light (1000 Lux) with a 16:8 h light/dark photoperiod in a growth chamber. Then, the shoot and root tissues of 26-day-old plantlets were collected for further analysis. The seeds of all genotypes were planted in peat:perlite:vermiculite in the ratio of 1:1:1 $(v / v / v)$. After seeds stratification, the plants were transferred into the growth chamber under the mentioned conditions. Sub-irrigation was performed every $48 \mathrm{~h}$ with a similar Hoagland's solution containing $1.25 \mathrm{mM} \mathrm{KH} \mathrm{PO}_{4}$ for 28 days. Subsequently, the seedlings were subjected to salt stress by applying 50,100, and $150 \mathrm{mM} \mathrm{NaCl}$ with the same Hoagland's solution, containing 1.25 $\mathrm{mMKH}_{2} \mathrm{PO}_{4}$ for 16 days. The control plants were grown without the addition of $\mathrm{NaCl}$.

\section{Measurement of Parameters}

All samples (shoots and roots) were oven-dried for $48 \mathrm{~h}$ at $70^{\circ} \mathrm{C}$. The amounts of photosynthetic leaf pigments (chlorophyll $a, b$, and carotenoid) were estimated, using acetone (80\%), proposed by Arnon (1967). Total available carbohydrates content, water-soluble, and insoluble carbohydrate were assayed using the Sheligl (1986) method. Total protein concentration was determined according to Bradford (1976), using bovine serum albumin (BSA) as a standard. The content of malondialdehyde (MDA) was measured through the thiobarbituric acid (TBA) reaction as described by Hodges et al. (1999). The capacity of $\mathrm{H}_{2} \mathrm{O}_{2}$ accumulation in leaves was obtained after $\mathrm{H}_{2} \mathrm{O}_{2}$ reaction with potassium iodide (KI), following the method proposed by Alexieva et al. (2001). Guaiacol peroxidase (POD) activity was analyzed according to Malik and Singh (1980), catalase (CAT) activity was measured according to the method of Aebi (1974) and ascorbate peroxidase (APX) activity was assayed as described by Nakano and Asada (1981). Measurement of total anthocyanin and flavonoid contents were quantified based on the Krizek et al. (1998) method. Proline content was obtained by following the method of Bates et al. (1973) and glycine betaine was performed according to Grieve and Grattan (1983). The content of $\mathrm{Na}^{+}$and $\mathrm{K}^{+}$were measured by using the flame spectrometry according to Hamada and El-Enany (1994). The spectrophotometric measurement of total and organic phosphate content was performed by following the method described by Ames (1966). Pi released by APase activity was evaluated using $p$-nitrophenyl phosphate ( $p$-NPP) as a generic phosphatase substrate according to Naseri et al. (2004). The yield and yield components of treated pot-grown plants were estimated by evaluating the flowering percent, pods number per plant, seeds number per each pod, and 1000-seed weight obtained during the salt stress period. Finally, the total seed yield (total seed yield obtained from pods N. $\times$ seeds N. per each pod $\times 1000$-seed weight) was also calculated for all plants.

\section{cDNA Synthesis and Gene Expression Analysis}

Total RNA was extracted from shoot and root tissues, using RNX reagent (Cinaclon BioScience Co., Iran) according to the manufacturer's instruction. The RNA samples were further treated with RNase A-free DNase (Roche, Basel, Switzerland) according to the supplier instruction to eliminate genomic DNA contamination. For cDNA synthesis, $1 \mu \mathrm{g}$ of DNase-treated RNA was reverse transcribed by M-MLV reverse transcriptase (Fermentas, Lithuania) as stated by the manufacturing instructions. A series of semi-quantitative RTPCR was conducted to evaluate the level of relative gene transcript variants (Zamani et al., 2012; Sabet et al., 2018), and their band intensity in agarose gel was quantified by TotalLab software (Phoretix International, New Castle, United Kingdom). The RT-PCR conditions were as follows: $94^{\circ} \mathrm{C}$ for $5 \mathrm{~min}$; 35 cycles of $94^{\circ} \mathrm{C}$ for $1 \mathrm{~min}$, specific annealing temperature for each primer pair for $1 \mathrm{~min}$ and $72^{\circ} \mathrm{C}$ for $1 \mathrm{~min}$; and a final extension step at $72^{\circ} \mathrm{C}$ for $10 \mathrm{~min}$. The $\alpha$-tubulin was used as the internal control gene to normalize the expression level in the semi-quantitative RT-PCR. the primers of SOS3, SOS2, HKT1, NHX1, AVP1, SOS1, $P A P 17, P A P 26$, and $\alpha$-tubulin genes in A. thaliana were designed by Oligo 7 software (Table 1 ).

\section{Statistical Analysis}

Analysis of variance (ANOVA) was conducted based on a randomized complete block design (RCBD) with three replicates (45 seedlings in vitro and 15 seedlings in vivo studied in each replicate/treatment) to detect the statistically significant effects of different treatments. The significant mean differences were evaluated by Fisher's least significant difference (LSD) or the Student's $t$-test. Likewise, the regression slope and the correlation coefficient levels of significance (for the relationship between the variables $)$ are represented by ${ }^{*}(P \leq 0.05),{ }^{* *}(P \leq 0.01)$, and ns (non-significant; $P>0.05$ ). To provide a global overview of the impacts of AtPAP17 and AtPAP26 on all measured parameters, hierarchical clustering analysis of variance normalized data was performed as a heat map, using http://www.metaboanalyst.ca/ faces/upload/StatUploadView.xhtml. A heat map of Pearson's correlation selected correlation and principal component analysis were also carried out through the website. Other statistical analyses were performed using SAS V. 9.2 and SPSS V. 22 software at $P<0.05$. 
TABLE 1 | The sequences of each primer pair used to PCR.

\begin{tabular}{|c|c|c|}
\hline Gene name & Accession number & Primer sequence \\
\hline \multirow[t]{2}{*}{$\alpha$-Tubulin } & AT4G14960 & 5'-GCTTCAACACCTTCTTCAG-3' \\
\hline & & 5'-GAATAGTTCGCTTGGTCTT-3' \\
\hline \multirow[t]{2}{*}{ AtSOS1 } & AT2G01980 & 5'-TCTCTTCGTCGGAATGTCTCTGG-3' \\
\hline & & 5'-TAAGCCAGTCAGCAGGTCCTAGC-3' \\
\hline \multirow[t]{2}{*}{ Atsos2 } & AT5G35410 & 5'-AACGGATCTGCACGGACGTTCG-3' \\
\hline & & 5'AGCTAACTGTCCGGCCTTGATCG-3' \\
\hline \multirow[t]{2}{*}{ Atsos3 } & AT5G24270 & 5'-CCGAGCTTCTTGCATCCGTCAC-3' \\
\hline & & 5'-GCACAGTACACAAGGCAAGTCCA-3' \\
\hline \multirow[t]{2}{*}{ AtNHX1 } & AT5G27150 & 5'-AGCAAGGGACCGTACACGTCTC-3' \\
\hline & & 5'-TCAGACCGGTTGCAGCACCAAGC-3' \\
\hline \multirow[t]{2}{*}{ AtHKT1 } & AT4G10310 & 5'-GAGGATCGCTGTGACGTTGAGACTG-3' \\
\hline & & 5'-GCAGCCACCATCGCTGATGTC-3' \\
\hline \multirow[t]{2}{*}{ AtAVP1 } & AT1G15690 & 5'-TGCATTCAGGTCTGGTGCTGTGATG-3' \\
\hline & & 5-GCTCCAATAGCAGCAGTGGTGTT-3' \\
\hline \multirow[t]{2}{*}{ AtPAP17 } & АT3G17790 & 5'-CGAGTCTGAGTTTGCTGTTGT-3' \\
\hline & & 5'-ACATAAGAGTTGCGAGATGGAAC-3' \\
\hline \multirow[t]{2}{*}{ AtPAP26 } & AT5G34850 & 5'-ATAGGCGATATGGGTCAGACATTC-3' \\
\hline & & 5'-CAGCGTACCAAAGAGGACTGCTAC-3' \\
\hline
\end{tabular}

\section{RESULTS}

\section{AtPAP17 and AtPAP26 Are Involved in Salt Tolerance \\ Biomass Assessments}

To investigate the final effect of salt stress and the response of different genotypes, biomass production was measured, and therein, salt stress caused a strong reduction of biomass in all genotypes studied (Table 2). Nevertheless, the decline was highly dependent on the level of $\mathrm{NaCl}$ concentrations and the genotypes as well. Our results showed that salinity inhibited the shoots' growth more than that of the roots in all genotypes $(t<0.01)$. With $\mathrm{NaCl}$ concentration increasing in the growth medium (50 to $150 \mathrm{mM}$ ), overexpressed and mutant plants showed the lowest and highest reduction in fresh and dry weight of shoots and roots compared to the wild-type ones, respectively (Table 2). In addition, comparing the genotypes in $100 \mathrm{mM} \mathrm{NaCl}$, knockout mutation of PAP17 and PAP26 genes led to a decrease in the fresh and dry weight of shoots and roots in mutant plants (Mu17, Mu26, and DM) compared to those in WT plants (Table 2). However, a significant increase of the parameters was presented in each overexpressed genotype (OE17 and OE26) in $150 \mathrm{mM}$ $\mathrm{NaCl}$ comparing with control plants (Table 2).

\section{Photosynthesis Capacity of Overexpress and Mutant Plants \\ Carbohydrates content}

Total carbohydrates content also decreased in all genotypes studied with increasing $\mathrm{NaCl}$ concentration (Table 2). In all concentrations of 50,100, and $150 \mathrm{mM} \mathrm{NaCl}, \mathrm{OE} 17$ and Mu17 plants showed a significant increase and decrease in the content of total carbohydrate content as compared to Col-0, respectively (Table 2). Moreover, simultaneous knockout mutation of PAP17 and PAP26 gens resulted in significantly lower accumulation of total carbohydrates in DM genotypes compared to that of WT plants in the three concentrations (Table 2). Interestingly, such results were not observed in OE26 and Mu26 genotypes (Table 2).

Further investigations showed that water-soluble and insoluble carbohydrate content also decreased in WT plants with increasing $\mathrm{NaCl}$ concentration (Figure 1). Despite this, the rate of reduction of soluble carbohydrate content was significantly lower $(t<0.05)$ than that for insoluble carbohydrate at the same conditions (Figure 1). Increasing $\mathrm{NaCl}$ concentration up to $50 \mathrm{mM}$, nonetheless, the rate of soluble carbohydrate increased in the overexpressed genotypes $\left(\mathrm{b}_{O E 17}=0.75\right.$ and $\left.\mathrm{b}_{O E 26}=0.52\right)$. In fact, the trend of soluble carbohydrate in $\mathrm{OE}$ plants was significantly $(t<0.05)$ in the opposite direction to that in WT seedlings $\left(\mathrm{b}_{W T}=-0.73\right)$ (Figure 1). Rising $\mathrm{NaCl}$ concentration to 100 and $150 \mathrm{mM}$ led to a decrease in soluble carbohydrates of $\mathrm{OE}$ genotypes; however, the reduction was significantly lower $\left(\mathrm{b}_{O E 17}=-0.14\right.$ and $\left.\mathrm{b}_{O E 26}=0.20, t<0.05\right)$ than that in WT plants $\left(\mathrm{b}_{W T}=0.82\right)$ (Figure $\left.\mathbf{1}\right)$.

The soluble carbohydrate content was significantly 2.16 -fold and 1.33-fold higher in OE17 and OE26 than that in WT plants under $150 \mathrm{mM} \mathrm{NaCl}$, respectively (Figure 1). Although overexpression of PAP26 has not resulted in significant changes in the total carbohydrate amount, the soluble carbohydrate content of OE26 plants was significantly higher than that in WT seedlings under $150 \mathrm{mM} \mathrm{NaCl}$ (Figure 1). The knockout mutation of PAP17 and PAP26 caused a significant decrease in soluble carbohydrates of Mu17, Mu26, and DM plants as compared to Col-0 in $150 \mathrm{mM} \mathrm{NaCl}$ (Figure 1).

\section{Photosynthetic pigments stability}

In all genotypes, chlorophyll $a$ content decreased with increasing $\mathrm{NaCl}$ concentration in the culture media (Table 2). With rising $\mathrm{NaCl}$ concentration from 0 to $150 \mathrm{mM}$, the overexpressed and mutant genotypes showed the lowest and highest reduction in chlorophyll $a$ content compared to that in WT plants (Table 2). Increasing of $\mathrm{NaCl}$ level from 0 to $150 \mathrm{mM}$ led to a decrease in chlorophyll $b$ and carotenoids content in all genotypes studied. However, the $\mathrm{OE}$ and mutant genotypes exhibited the lowest and highest reduction in those compared with WT plants (Table 2). According to the results, OE17 and OE26 seedlings showed significantly higher chlorophyll $a, b$, and carotenoid content in $150 \mathrm{mM} \mathrm{NaCl}$, while the relative contents were significantly lower in mutant genotypes than those in wild-type plants (Table 2).

\section{The Cellular Role of AtPAP17 and AtPAP26 Under Salt Stress}

\section{Facilitating Water Retention}

Overproduction of compatible organic solutes is one of the most common plants' responses to physiological water deficit that are known to accumulate under salt stress in many crops (Munns and Tester, 2008). Here, with increasing $\mathrm{NaCl}$ concentration in the culture media, proline (shoots and roots) and glycine betaine content increased in all genotypes gradually, but differently for each genotype (Table 3 ). The overexpression of AtPAP17 and AtPAP26 genes led to a significant increase in proline (shoots and roots) and glycine betaine content in OE17 and OE26 plants. The relative contents, however, were significantly lower in Mu17, Mu26, and DM plants as compared 
TABLE 2 | Means ( \pm SE) of the fresh and dry weight, total carbohydrate, and photosynthetic pigments contents in genotypes subjected to NaCl concentrations.

\begin{tabular}{|c|c|c|c|c|c|c|c|c|c|}
\hline & \multirow[t]{2}{*}{ Genotype } & \multicolumn{2}{|c|}{$\begin{array}{l}\text { Fresh weight } \\
\left(\text { mg plant }^{-1}\right)\end{array}$} & \multicolumn{2}{|c|}{$\begin{array}{l}\text { Dry weight } \\
\left(\mathrm{mg} \mathrm{plant}^{-1}\right)\end{array}$} & \multirow[t]{2}{*}{$\begin{array}{l}\text { Total carbohydrate } \\
\left(\mathrm{mg} \mathrm{g}^{-1} \mathrm{DW} \text { plant }\right. \\
\end{array}$} & \multicolumn{3}{|c|}{$\begin{array}{l}\text { Photosynthetic pigments } \\
\left.\qquad \text { (mg g }^{-1} \mathrm{FW} \text { plant }^{-1}\right)\end{array}$} \\
\hline & & Shoot & Root & Shoot & Root & & Chlorophyll a & Chlorophyll b & Carotenoid \\
\hline $\mathrm{OmM}$ & WT & $36.67 \pm 2.77^{c}$ & $9.07 \pm 0.16^{b}$ & $30.22 \pm 1.21^{c}$ & $7.00 \pm 1.11^{\mathrm{b}}$ & $24.31 \pm 0.46^{c}$ & $1.79 \pm 0.08^{a b}$ & $1.05 \pm 0.48^{a}$ & $0.63 \pm 0.04^{\mathrm{cb}}$ \\
\hline \multirow[t]{5}{*}{$\mathrm{NaCl}$} & Mu17 & $30.16 \pm 2.86^{d}$ & $11.70 \pm 0.82^{a}$ & $22.91 \pm 2.12^{d}$ & $9.16 \pm 0.73^{a}$ & $25.18 \pm 1.62^{c}$ & $1.64 \pm 0.11^{b}$ & $1.24 \pm 0.03^{a}$ & $0.64 \pm 0.08^{b}$ \\
\hline & Mu26 & $32.78 \pm 1.68^{d}$ & $11.87 \pm 0.61^{a}$ & $26.18 \pm 1.18^{d}$ & $9.38 \pm 0.51^{a}$ & $12.58 \pm 0.61^{\mathrm{e}}$ & $1.59 \pm 0.07^{b}$ & $1.19 \pm 0.11^{a}$ & $0.57 \pm 0.02^{\mathrm{cb}}$ \\
\hline & $\mathrm{DM}$ & $42.89 \pm 1.93^{b}$ & $12.15 \pm 0.27^{a}$ & $36.12 \pm 1.74^{\mathrm{ab}}$ & $9.60 \pm 0.23^{a}$ & $20.78 \pm 0.50^{d}$ & $1.61 \pm 0.21^{b}$ & $1.15 \pm 0.06^{a}$ & $0.55 \pm 0.04^{c}$ \\
\hline & OE17 & $46.91 \pm 1.28^{\mathrm{a}}$ & $11.51 \pm 0.64^{a}$ & $38.72 \pm 2.03^{a}$ & $8.87 \pm 0.51^{a}$ & $42.81 \pm 1.47^{\mathrm{a}}$ & $1.98 \pm 0.15^{\mathrm{a}}$ & $1.43 \pm 0.13^{\mathrm{a}}$ & $0.79 \pm 0.03^{a}$ \\
\hline & OE26 & $42.00 \pm 0.56^{b}$ & $7.95 \pm 0.35^{\mathrm{c}}$ & $34.86 \pm 1.44^{b}$ & $5.95 \pm 0.44^{b}$ & $29.17 \pm 0.57^{b}$ & $2.01 \pm 0.24^{a}$ & $1.37 \pm 0.17^{a}$ & $0.73 \pm 0.04^{a}$ \\
\hline $50 \mathrm{mM}$ & WT & $24.20 \pm 1.70^{c}$ & $10.31 \pm 0.56^{\mathrm{cb}}$ & $18.00 \pm 2.01^{c}$ & $8.08 \pm 0.52^{a}$ & $22.55 \pm 1.66^{b}$ & $1.23 \pm 0.82^{b}$ & $1.46 \pm 0.05^{b}$ & $0.54 \pm 0.06^{b}$ \\
\hline \multirow[t]{5}{*}{$\mathrm{NaCl}$} & Mu17 & $21.16 \pm 1.34^{d}$ & $13.78 \pm 0.47^{a}$ & $14.58 \pm 0.61^{d}$ & $8.58 \pm 0.25^{a}$ & $14.04 \pm 0.77^{d}$ & $0.50 \pm 0.03^{d}$ & $0.61 \pm 0.04^{d}$ & $0.46 \pm 0.02^{c}$ \\
\hline & Mu26 & $19.43 \pm 1.70^{d}$ & $10.52 \pm 0.52^{b}$ & $11.76 \pm 0.67^{e}$ & $8.09 \pm 0.51^{a}$ & $17.47 \pm 0.44^{c}$ & $1.03 \pm 0.20^{\mathrm{cb}}$ & $0.77 \pm 0.04^{d}$ & $0.43 \pm 0.02^{c}$ \\
\hline & $\mathrm{DM}$ & $35.00 \pm 0.80^{b}$ & $8.73 \pm 0.67^{d}$ & $27.85 \pm 0.68^{a}$ & $6.62 \pm 0.53^{b}$ & $17.24 \pm 1.11^{\mathrm{c}}$ & $0.98 \pm 0.14^{c}$ & $1.02 \pm 0.18^{\mathrm{C}}$ & $0.34 \pm 0.04^{d}$ \\
\hline & OE17 & $43.02 \pm 1.82^{a}$ & $9.96 \pm 0.98^{\mathrm{cb}}$ & $27.35 \pm 1.71^{a}$ & $7.68 \pm 0.50^{a b}$ & $29.96 \pm 0.63^{a}$ & $1.86 \pm 0.06^{a}$ & $1.91 \pm 0.11^{\mathrm{a}}$ & $0.78 \pm 0.06^{a}$ \\
\hline & OE26 & $36.42 \pm 1.70^{b}$ & $9.61 \pm 0.63^{c}$ & $21.68 \pm 0.93^{b}$ & $6.67 \pm 0.81^{b}$ & $23.03 \pm 0.86^{b}$ & $1.65 \pm 0.16^{a}$ & $1.47 \pm 0.09^{b}$ & $0.61 \pm 0.02^{b}$ \\
\hline $100 \mathrm{mM}$ & WT & $18.36 \pm 0.78^{b}$ & $9.07 \pm 0.26^{a}$ & $12.94 \pm 0.70^{c}$ & $7.12 \pm 0.75^{a}$ & $18.59 \pm 0.53^{b}$ & $0.51 \pm 0.04^{c}$ & $0.84 \pm 0.13^{c}$ & $0.44 \pm 0.07^{b}$ \\
\hline \multirow[t]{5}{*}{$\mathrm{NaCl}$} & Mu17 & $14.20 \pm 1.32^{c}$ & $6.21 \pm 0.78^{b}$ & $7.94 \pm 0.42^{d}$ & $4.57 \pm 0.53^{b}$ & $11.44 \pm 1.30^{\circ}$ & $0.30 \pm 0.02^{d}$ & $0.48 \pm 0.04^{e}$ & $0.16 \pm 0.01^{c}$ \\
\hline & Mu26 & $15.21 \pm 0.57^{c}$ & $4.98 \pm 0.99^{b}$ & $8.00 \pm 0.18^{d}$ & $3.40 \pm 0.63^{\mathrm{C}}$ & $9.17 \pm 0.92^{d}$ & $0.45 \pm 0.04^{\mathrm{cd}}$ & $0.64 \pm 0.07^{d}$ & $0.39 \pm 0.04^{b}$ \\
\hline & $\mathrm{DM}$ & $13.47 \pm 0.37^{c}$ & $2.66 \pm 0.28^{c}$ & $8.48 \pm 1.01^{d}$ & $2.37 \pm 0.81^{d}$ & $12.13 \pm 1.01^{\mathrm{c}}$ & $0.49 \pm 0.03^{c}$ & $0.67 \pm 0.05^{d}$ & $0.24 \pm 0.01^{c}$ \\
\hline & OE17 & $32.42 \pm 0.51^{a}$ & $8.90 \pm 0.52^{a}$ & $23.90 \pm 0.54^{a}$ & $6.87 \pm 0.39^{a}$ & $33.85 \pm 1.73^{a}$ & $1.05 \pm 0.15^{\mathrm{a}}$ & $1.29 \pm 0.12^{\mathrm{a}}$ & $0.61 \pm 0.03^{a}$ \\
\hline & OE26 & $31.46 \pm 3.62^{a}$ & $8.64 \pm 1.34^{a}$ & $21.37 \pm 1.21^{b}$ & $6.40 \pm 0.31^{a}$ & $11.76 \pm 1.01^{\mathrm{c}}$ & $0.88 \pm 0.04^{b}$ & $1.07 \pm 0.05^{b}$ & $0.58 \pm 0.00^{\mathrm{a}}$ \\
\hline $150 \mathrm{mM}$ & WT & $13.60 \pm 0.76^{c}$ & $3.98 \pm 0.52^{b}$ & $8.26 \pm 1.08^{c}$ & $2.77 \pm 0.42^{b}$ & $9.45 \pm 0.33^{c}$ & $0.41 \pm 0.03^{b}$ & $0.57 \pm 0.09^{c}$ & $0.29 \pm 0.04^{b}$ \\
\hline \multirow[t]{5}{*}{$\mathrm{NaCl}$} & Mu17 & $7.51 \pm 0.23^{e}$ & $1.98 \pm 0.06^{c}$ & $5.63 \pm 0.29^{d}$ & $0.75 \pm 0.06^{d}$ & $3.96 \pm 1.08^{\mathrm{e}}$ & $0.13 \pm 0.01^{d}$ & $0.15 \pm 0.06^{f}$ & $0.10 \pm 0.01^{d}$ \\
\hline & Mu26 & $9.71 \pm 0.28^{d}$ & $2.98 \pm 0.12^{\mathrm{cb}}$ & $4.64 \pm 0.59^{d}$ & $1.74 \pm 0.10^{\mathrm{c}}$ & $11.11 \pm 0.34^{b}$ & $0.29 \pm 0.06^{c}$ & $0.44 \pm 0.05^{d}$ & $0.21 \pm 0.01^{c}$ \\
\hline & $\mathrm{DM}$ & $8.07 \pm 0.77^{e}$ & $3.19 \pm 0.24^{\mathrm{cb}}$ & $5.51 \pm 0.60^{d}$ & $1.93 \pm 0.18^{\mathrm{c}}$ & $6.76 \pm 0.69^{d}$ & $0.18 \pm 0.03^{d}$ & $0.27 \pm 0.07^{e}$ & $0.16 \pm 0.01^{c}$ \\
\hline & OE17 & $25.70 \pm 1.00^{\mathrm{a}}$ & $7.54 \pm 1.11^{a}$ & $19.60 \pm 1.58^{a}$ & $5.72 \pm 0.78^{a}$ & $18.75 \pm 0.98^{a}$ & $0.62 \pm 0.05^{\mathrm{a}}$ & $1.03 \pm 0.07^{a}$ & $0.46 \pm 0.03^{a}$ \\
\hline & OE26 & $22.54 \pm 1.48^{b}$ & $6.77 \pm 0.81^{a}$ & $16.71 \pm 1.45^{\mathrm{b}}$ & $5.10 \pm 0.62^{a}$ & $10.04 \pm 0.64^{c b}$ & $0.55 \pm 0.02^{\mathrm{a}}$ & $0.74 \pm 0.03^{b}$ & $0.42 \pm 0.33^{a}$ \\
\hline
\end{tabular}

For each level of $\mathrm{NaCl}$ concentration, the significant differences between means were shown with different letters at $P<0.05$.

to those in WT seedlings at $150 \mathrm{mM} \mathrm{NaCl}$ concentration (Table 3). Interestingly, the proline content was significantly more concentrated $(t<0.01)$ in roots than in shoots at $150 \mathrm{mM}$ $\mathrm{NaCl}$ (Table 3).

\section{Maintenance of Cellular Stability Lipid peroxidation assay}

In all genotypes, increasing $\mathrm{NaCl}$ concentration (50,100, and $150 \mathrm{mM}$ ) resulted in a gradual increase of MDA, as a biomarker of lipid peroxidation (Table 3). This alteration could represent the increase of salt stress sensing and/or low efficiency in ROS scavenging and cell damage management. Examination of the responses to salt stress displayed dissimilar feedback in the genotypes where the overexpressed and mutant plants showed dramatically the lowest and the highest increase in MDA amount compared to WT plants, with increasing $\mathrm{NaCl}$ concentration (Table 3). In 100 and $150 \mathrm{mM} \mathrm{NaCl}$, the MDA content of OE17 and OE26 plants were also significantly lower than to Col-0, while Mu17, Mu26, and DM seedlings had significantly more accumulation of MDA content compared to the control ones (Table 3 ).

\section{Hydrogen peroxide-induced response}

Salt stress $\left(50,100\right.$, and $150 \mathrm{mM} \mathrm{NaCl}$ ) also increased $\mathrm{H}_{2} \mathrm{O}_{2}$ accumulation in all genotypes. The lowest increase belonged to OE26 and OE17 plants, but Mu26 showed the most increase in $\mathrm{H}_{2} \mathrm{O}_{2}$ accumulation among other genotypes (Table 3). Also, the overexpressed plants (OE17 and OE26) showed a significantly lower amount of $\mathrm{H}_{2} \mathrm{O}_{2}$, while Mu26 and DM plants had more amount of $\mathrm{H}_{2} \mathrm{O}_{2}$ compared to WT seedlings at $150 \mathrm{mM}$ $\mathrm{NaCl}$ (Table 3).

\section{Oxidative stress adaptation}

Enzymatic antioxidants activity. With rising $\mathrm{NaCl}$ concentration from 0 to $150 \mathrm{mM}$, the highest increase in APX, CAT, and POX activities belonged to the overexpressed plants, while the mutant genotypes showed the lowest increase compared to the wild-types (Table 3). In $150 \mathrm{mM} \mathrm{NaCl}$, overexpression and knockout mutation of PAP17 and PAP26 also resulted in significantly higher and lower activities in CAT and POX enzymes in overexpressed and mutant genotypes compared to WT seedlings, respectively (Table 3). Interestingly, the observed differences were more 

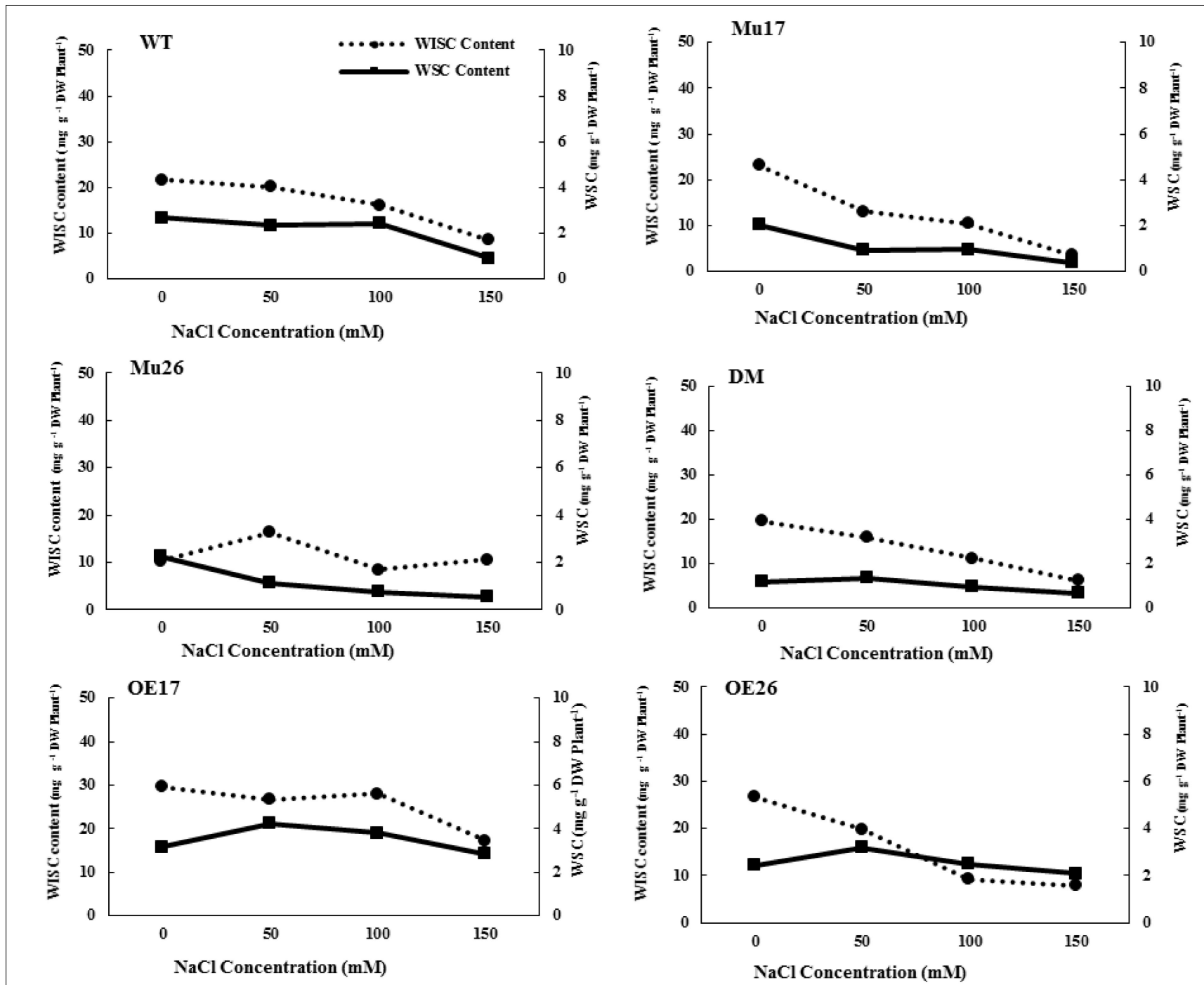

FIGURE 1 | Trend of water-soluble carbohydrate (WSC) and water-insoluble carbohydrate (WISC) on genotypes subjected to NaCl stress. Wild type (WT), overexpress (OE), single mutant (Mu) and double mutant (DM) genotypes of Arabidopsis thaliana purple acid phosphatase 17 (AtPAP17) and 26 (AtPAP26) genes.

in OE17 shoots, and following that, OE26 shoots at the same condition (Table 3).

Non-enzymatic antioxidants activity. No significant differences were detected among genotypes in anthocyanin as well as flavonoid content in different conditions (data not shown).

\section{Regulation of $\mathrm{Na}^{+}$and $\mathrm{K}^{+}$Fluxes}

Rising $\mathrm{NaCl}$ concentration from 0 to $150 \mathrm{mM}$ increased $\mathrm{Na}^{+}$ and decreased $\mathrm{K}^{+}$content in both shoots and roots. The changes were different in the various genotypes where overexpressed plants showed the lowest increase and decrease in $\mathrm{Na}^{+}$and $\mathrm{K}^{+}$ accumulation, respectively (Figure 2 ). On the other hand, the highest increase in $\mathrm{Na}^{+}$accumulation, and a decrease in $\mathrm{K}^{+}$ accumulation belonged to the mutant plants compared to WT ones (Figure 2).

The accumulation of $\mathrm{Na}^{+}$in shoots was on average $20.01 \%$ $(t<0.01)$ more than that in roots, at $150 \mathrm{mM} \mathrm{NaCl}$. In this concentration of $\mathrm{NaCl}$, overexpression of PAP17 and PAP26 also caused a significantly lower accumulation of $\mathrm{Na}^{+}$in shoots and roots of OE genotypes compared to that in WT plants (Figure 2). The knockout mutation of these two genes resulted in a significant accumulation of $\mathrm{Na}^{+}$in shoots and roots of all mutant plants compared with WTs at the same condition (Figure 2). Despite these results, the rate of accumulation of $\mathrm{K}^{+}$ was more in shoots and roots of $\mathrm{OE}$ and less in mutant plants compared to WT seedlings following $150 \mathrm{mM} \mathrm{NaCl}$ (Figure 2).

Finally, the consequence of PAP17 and PAP26 activities in the regulation of $\mathrm{Na}^{+}$and $\mathrm{K}^{+}$accumulation modified $\mathrm{K}^{+} / \mathrm{Na}^{+}$ ratio both in shoots and roots (Figure 3) where the $\mathrm{K}^{+} / \mathrm{Na}^{+}$ ratio of overexpressed plants was significantly higher than WT plants under $150 \mathrm{mM} \mathrm{NaCl}$. Conversely, the relative ratio in shoots and roots of Mu17, Mu26, and DM plants was significantly less than the control ones at the same $\mathrm{NaCl}$ concentration (Figure 3). The correlation coefficient between $\mathrm{K}^{+} / \mathrm{Na}^{+}$ratio and 
TABLE 3 | Means ( \pm SE) of the physiological and biochemical parameters in genotypes subjected to the $\mathrm{NaCl}$ concentrations.

\begin{tabular}{|c|c|c|c|c|c|c|c|c|c|}
\hline & \multirow[t]{2}{*}{ Genotype } & \multicolumn{2}{|c|}{ 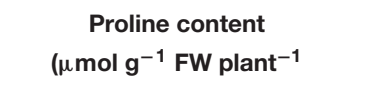 } & \multirow{2}{*}{$\begin{array}{l}\text { GB content } \\
\left(\mu \mathrm{mol} \mathrm{g}^{-1}\right. \\
\text { FW plant } \\
\end{array}$} & \multirow{2}{*}{$\begin{array}{l}\text { MDA content } \\
(\mu \mathrm{mol} \\
\mathrm{mg}^{-1} \mathrm{FW}\end{array}$} & \multirow[t]{2}{*}{$\begin{array}{c}\mathrm{H}_{2} \mathrm{O}_{2} \text { content } \\
\left(\mu \mathrm{mol} \mathrm{mg} \mathrm{mg}^{-1} \mathrm{FW}\right)\end{array}$} & \multirow[t]{2}{*}{$\begin{array}{c}\text { APX } \\
\left(\mathrm{U} \mathrm{g}^{-1} \mathrm{FW}\right)\end{array}$} & \multirow[t]{2}{*}{$\begin{array}{c}\text { POX } \\
\left(\mathrm{Ug}^{-1} \mathrm{FW}\right)\end{array}$} & \multirow[t]{2}{*}{$\begin{array}{c}\text { CAT } \\
\left(\mathrm{U} \mathrm{g}^{-1} \mathrm{FW}\right)\end{array}$} \\
\hline & & Shoot & Root & & & & & & \\
\hline $0 \mathrm{mM}$ & WT & $3.05 \pm 0.21^{b}$ & $5.08 \pm 0.47^{c}$ & $1.97 \pm 0.52^{a}$ & $1.29 \pm 0.10^{\mathrm{cb}}$ & $0.08 \pm 0.01^{a b}$ & $0.00 \pm 0.00^{c}$ & $3.02 \pm 0.09^{d}$ & $1.15 \pm 0.25^{\mathrm{e}}$ \\
\hline \multirow[t]{5}{*}{$\mathrm{NaCl}$} & Mu17 & $3.01 \pm 0.42^{b}$ & $5.02 \pm 0.52^{\mathrm{C}}$ & $1.94 \pm 0.38^{a}$ & $1.40 \pm 0.05^{\mathrm{b}}$ & $0.09 \pm 0.01^{\mathrm{ab}}$ & $1.25 \pm 0.32^{\mathrm{a}}$ & $6.24 \pm 0.47^{b}$ & $4.60 \pm 0.23^{c}$ \\
\hline & Mu26 & $2.09 \pm 0.16^{c}$ & $3.48 \pm 0.26^{d}$ & $1.81 \pm 0.13^{a}$ & $1.65 \pm 0.15^{a}$ & $0.08 \pm 0.00^{\mathrm{b}}$ & $0.85 \pm 0.54^{a b}$ & $5.18 \pm 0.26^{c}$ & $5.23 \pm 0.32^{b}$ \\
\hline & $\mathrm{DM}$ & $2.31 \pm 0.20^{\mathrm{C}}$ & $4.72 \pm 0.64^{\mathrm{c}}$ & $2.00 \pm 0.1^{7 a}$ & $1.34 \pm 0.10^{\mathrm{cb}}$ & $0.10 \pm 0.03^{a b}$ & $0.40 \pm 0.16^{b c}$ & $7.18 \pm 0.11^{a}$ & $6.50 \pm 0.57 a$ \\
\hline & OE17 & $1.39 \pm 0.30^{d}$ & $8.10 \pm 0.75^{a}$ & $1.20 \pm 0.47^{a}$ & $1.19 \pm 0.10^{c}$ & $0.08 \pm 0.01^{b}$ & $0.00 \pm 0.00^{c}$ & $2.94 \pm 0.12^{\mathrm{d}}$ & $1.89 \pm 0.27^{d}$ \\
\hline & OE26 & $4.17 \pm 0.52^{a}$ & $6.95 \pm 0.67^{b}$ & $2.27 \pm 0.15^{a}$ & $1.34 \pm 0.26^{\mathrm{cb}}$ & $0.10 \pm 0.01^{a}$ & $0.00 \pm 0.00^{c}$ & $2.74 \pm 0.33^{d}$ & $1.91 \pm 0.07^{d}$ \\
\hline $50 \mathrm{mM}$ & WT & $17.45 \pm 1.07^{\mathrm{c}}$ & $23.58 \pm 1.59^{c}$ & $8.10 \pm 0.34^{b}$ & $4.75 \pm 0.49^{b}$ & $0.12 \pm 0.22^{a b}$ & $1.02 \pm 0.22^{b}$ & $5.82 \pm 0.91^{e}$ & $6.67 \pm 0.66^{d}$ \\
\hline \multirow[t]{5}{*}{$\mathrm{NaCl}$} & Mu17 & $7.92 \pm 0.53^{\mathrm{e}}$ & $13.20 \pm 1.28^{\mathrm{e}}$ & $4.28 \pm 0.56^{c}$ & $4.44 \pm 0.41^{\mathrm{cb}}$ & $0.11 \pm 0.01^{a b}$ & $1.95 \pm 0.24^{a}$ & $15.76 \pm 0.26^{a}$ & $7.49 \pm 0.29^{c}$ \\
\hline & Mu26 & $9.20 \pm 0.33^{e d}$ & $15.33 \pm 1.55^{\mathrm{e}}$ & $4.97 \pm 1.07^{c}$ & $5.94 \pm 1.07^{\mathrm{a}}$ & $0.12 \pm 0.23^{a b}$ & $1.88 \pm 0.44^{a}$ & $14.24 \pm 0.54^{b}$ & $8.64 \pm 0.32^{b}$ \\
\hline & $\mathrm{DM}$ & $10.34 \pm 1.18^{d}$ & $17.24 \pm 2.24^{d}$ & $5.59 \pm 0.49^{c}$ & $4.24 \pm 0.18^{\mathrm{cb}}$ & $0.12 \pm 0.19^{a b}$ & $2.18 \pm 0.50^{a}$ & $12.51 \pm 0.64^{c}$ & $11.66 \pm 0.91^{a}$ \\
\hline & OE17 & $26.41 \pm 0.39^{a}$ & $35.33 \pm 0.91^{a}$ & $14.27 \pm 1.14^{\mathrm{a}}$ & $3.00 \pm 0.31^{\mathrm{cd}}$ & $0.11 \pm 0.01^{b}$ & $0.71 \pm 0.10^{b}$ & $5.23 \pm 0.39^{e}$ & $2.80 \pm 0.56^{f}$ \\
\hline & OE26 & $23.95 \pm 1.05^{b}$ & $30.65 \pm 1.25^{b}$ & $12.94 \pm 1.19^{a}$ & $3.57 \pm 0.17^{d}$ & $0.13 \pm 0.01^{a}$ & $0.90 \pm 0.43^{b}$ & $7.55 \pm 0.63^{d}$ & $5.24 \pm 0.31^{e}$ \\
\hline $100 \mathrm{mM}$ & WT & $17.77 \pm 0.60^{\mathrm{c}}$ & $30.48 \pm 0.64^{c}$ & $9.60 \pm 0.32^{b}$ & $5.94 \pm 0.05^{d}$ & $0.17 \pm 0.01^{\mathrm{b}}$ & $1.97 \pm 0.80^{c b}$ & $10.77 \pm 0.47^{d}$ & $8.09 \pm 0.69^{c}$ \\
\hline \multirow[t]{5}{*}{$\mathrm{NaCl}$} & Mu17 & $12.64 \pm 0.80^{e}$ & $21.06 \pm 0.96^{\mathrm{ed}}$ & $6.83 \pm 1.05^{c}$ & $8.11 \pm 0.49^{c}$ & $0.16 \pm 0.02^{b}$ & $1.65 \pm 0.16^{c}$ & $11.86 \pm 1.18^{d}$ & $9.27 \pm 0.33^{b}$ \\
\hline & Mu26 & $11.40 \pm 0.30^{f}$ & $18.99 \pm 0.50^{e}$ & $6.16 \pm 0.16^{c}$ & $10.54 \pm 0.54^{a}$ & $0.21 \pm 0.03^{a}$ & $2.13 \pm 0.40^{b}$ & $7.97 \pm 0.24^{\mathrm{e}}$ & $5.04 \pm 0.43^{d}$ \\
\hline & $\mathrm{DM}$ & $14.27 \pm 0.63^{d}$ & $23.79 \pm 0.90^{d}$ & $7.72 \pm 1.45^{\mathrm{c}}$ & $9.71 \pm 0.67^{b}$ & $0.25 \pm 0.04^{a}$ & $1.96 \pm 0.19^{c b}$ & $15.26 \pm 0.61^{c}$ & $9.35 \pm 0.63^{b}$ \\
\hline & OE17 & $30.45 \pm 0.73^{b}$ & $44.96 \pm 1.93^{b}$ & $16.46 \pm 1.47^{a}$ & $4.39 \pm 0.42^{\mathrm{e}}$ & $0.16 \pm 0.02^{b}$ & $2.99 \pm 0.39^{a}$ & $21.20 \pm 0.55^{\mathrm{a}}$ & $11.34 \pm 0.58^{a}$ \\
\hline & OE26 & $32.94 \pm 0.92^{a}$ & $51.42 \pm 2.89^{a}$ & $17.80 \pm 0.49^{a}$ & $3.82 \pm 0.33^{e}$ & $0.13 \pm 0.02^{b}$ & $2.68 \pm 0.12^{a}$ & $17.66 \pm 0.33^{b}$ & $10.56 \pm 0.30^{a}$ \\
\hline $150 \mathrm{mM}$ & WT & $23.67 \pm 0.99^{c}$ & $45.24 \pm 1.64^{c}$ & $12.80 \pm 1.16^{b}$ & $7.96 \pm 0.44^{d}$ & $0.26 \pm 0.02^{b}$ & $1.82 \pm 0.80^{\mathrm{cb}}$ & $12.57 \pm 0.65^{c}$ & $5.78 \pm 0.52^{c}$ \\
\hline \multirow[t]{5}{*}{$\mathrm{NaCl}$} & Mu17 & $10.13 \pm 0.71^{\mathrm{e}}$ & $26.44 \pm 2.12^{f}$ & $5.48 \pm 0.38^{d}$ & $9.25 \pm 0.67^{\mathrm{c}}$ & $0.28 \pm 0.03^{b}$ & $1.18 \pm 0.32^{\mathrm{cd}}$ & $5.98 \pm 0.25^{e}$ & $2.95 \pm 0.34^{e}$ \\
\hline & Mu26 & $11.90 \pm 0.28^{\mathrm{e}}$ & $31.42 \pm 2.03^{\mathrm{e}}$ & $6.43 \pm 0.15^{d}$ & $13.28 \pm 0.60^{a}$ & $0.31 \pm 0.30^{a}$ & $0.83 \pm 0.14^{d}$ & $6.24 \pm 0.15^{\mathrm{e}}$ & $3.75 \pm 0.80^{d}$ \\
\hline & $\mathrm{DM}$ & $18.28 \pm 0.59^{d}$ & $36.26 \pm 0.96^{d}$ & $9.88 \pm 0.32^{\mathrm{C}}$ & $11.52 \pm 0.59^{b}$ & $0.32 \pm 0.30^{a}$ & $1.51 \pm 0.67^{c}$ & $9.60 \pm 0.45^{d}$ & $1.31 \pm 0.67^{f}$ \\
\hline & OE17 & $36.81 \pm 2.03^{a}$ & $74.37 \pm 3.55^{a}$ & $16.90 \pm 1.11^{a}$ & $5.42 \pm 0.80^{e}$ & $0.14 \pm 0.30^{c}$ & $3.63 \pm 0.38^{a}$ & $23.24 \pm 0.56^{a}$ & $13.27 \pm 0.58^{a}$ \\
\hline & OE26 & $29.12 \pm 2.63^{b}$ & $60.11 \pm 2.94^{b}$ & $15.74 \pm 1.31^{a}$ & $6.20 \pm 0.09^{e}$ & $0.14 \pm 0.01^{\mathrm{c}}$ & $2.42 \pm 0.46^{b}$ & $16.05 \pm 1.46^{b}$ & $9.69 \pm 0.92^{b}$ \\
\hline
\end{tabular}

For each level of $\mathrm{NaCl}$ concentration, the significant differences between means were shown with different letters at $P<0.05$.

dry seedling weight was estimated $0.94(P<0.01)$, while 0.82 $(P<0.01)$ correlation was detected between $\mathrm{Na}^{+}$content and seedling dry weight.

\section{Transcriptional Profiling of Important Genes Involved in Plants $\mathrm{Na}^{+}$ Management}

The expression level of SOS3, SOS2, HKT1, NHX1, AVP1, and SOS1 genes were up-regulated by salt stress $(0-150 \mathrm{mM}$ $\mathrm{NaCl}$ ) in the roots and shoots of all genotypes (Figure 4). The changes of the expression levels were higher in the roots $(t<0.01)$ compared to shoots at the concentration of $\mathrm{NaCl}$. Thanks to the different genetic potential of genotypes, the increase in expression levels of the genes were proportionally dissimilar for each genotype, to respond to salinity stress.

In $150 \mathrm{mM} \mathrm{NaCl}$, the expression level of SOS3 gene was significantly higher in shoots and roots of the overexpressed plants as compared to the wild-type ones (Figure 4). The SOS2 gene expression level was significantly higher in shoots and roots of OE plants than WT, while the roots of mutant plants showed the lowest relative expression value under $150 \mathrm{mM}$
$\mathrm{NaCl}$ condition (Figure 4). The expression level of HKT1 gene was significantly higher in both roots and shoots of OE17 and OE26 plants compared to WT plants at $150 \mathrm{mM} \mathrm{NaCl}$. The significantly lower HKT1 expression was detected in shoots and roots of $\mathrm{Mu} 17$ under the same sodium concentration (Figure 4). Among all seedlings growing under $150 \mathrm{mM} \mathrm{NaCl}$, the OE17 (in shoots and roots) and OE26 (in shoots) exhibited significantly higher expression levels of NHX1 gene compared to WT plants. However, the lowest expression level of the gene was significantly measured in shoots of all mutant genotypes (Mu17, Mu26, and $\mathrm{DM}$ ), and roots of Mu26 genotype (Figure 4). The overexpression of PAP17 and PAP26 also significantly caused a higher expression level in AVP1 gene in shoots and roots of the overexpressed plants compared to Col-0 in $150 \mathrm{mM} \mathrm{NaCl}$. On the other hand, Knockout mutation of the genes in double-mutant plants resulted in significantly lower expression of $A V P 1$ gene in the plant's shoot and root as compared to WT plants (Figure 4). Overexpression and knockout mutation of PAP17 and PAP26 also resulted significantly in more expression level of SOS1 gene in both shoots and roots of OE plants and lower in mutant plants when compared to the control plants in $150 \mathrm{mM}$ sodium concentration (Figure 4). 


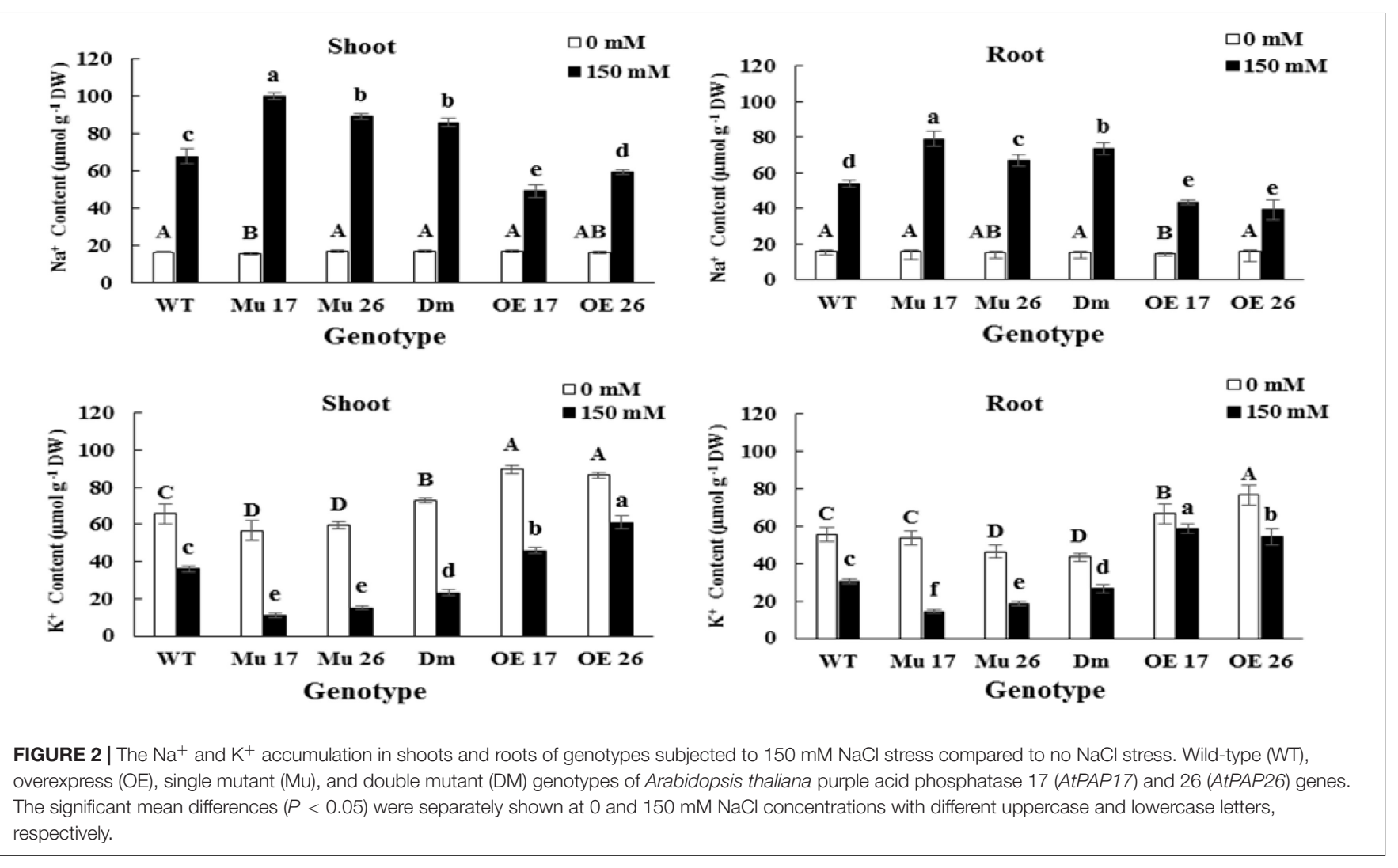

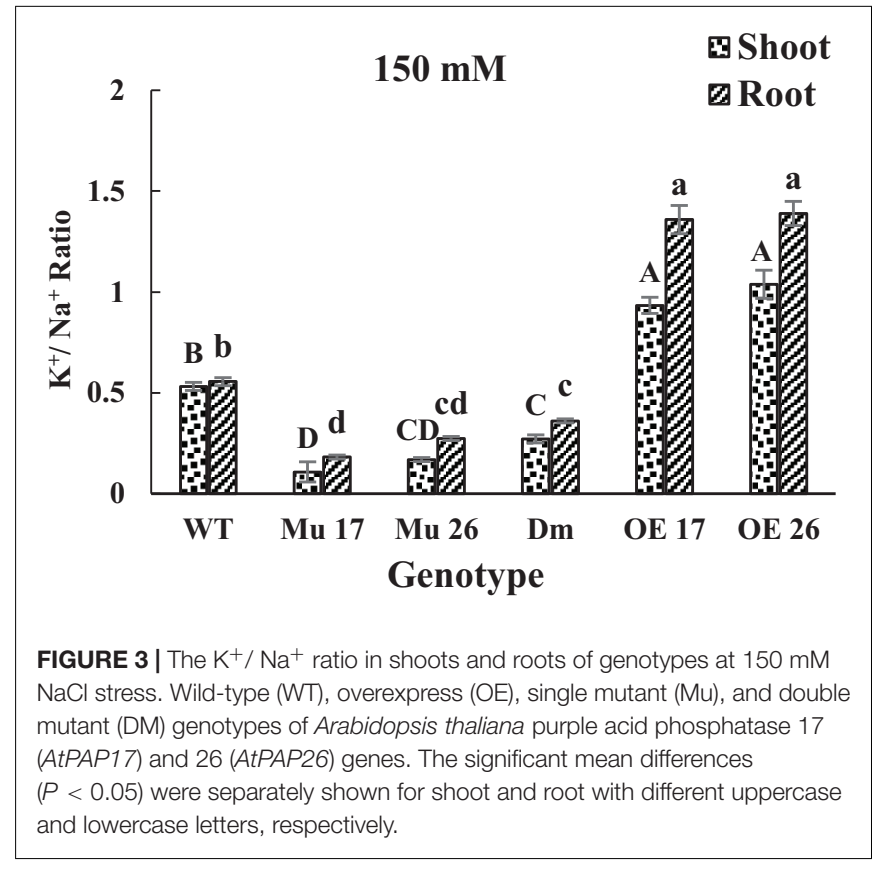

\section{Regulation of Phosphate Homeostasis} Total, Inorganic, and Organic Phosphate Content To investigate systematically the role of PAP17 and PAP26 in phosphorus supply, total phosphate content, inorganic ( $\mathrm{Pi})$, and organic phosphate $(\mathrm{Po})$ content were estimated in both shoots and roots of the plants treated with $0,50,100$, and $150 \mathrm{mM}$ $\mathrm{NaCl}$. The total P content was obviously affected by salt stress in shoots and roots of genotypes studied while rising $\mathrm{NaCl}$ concentration to 50,100, and $150 \mathrm{mM}$ (Table 4). Our results clearly demonstrated that overexpression of PAP17 and PAP26 genes led to the lowest rate of reduction of total $\mathrm{P}$ content in $\mathrm{OE}$ seedling under saline conditions (Table 4). At the same condition, however, the knockout mutation of the genes caused the most rate of total $\mathrm{P}$ content reduced in mutant plants (Table 4). Furthermore, the total $\mathrm{P}$ content in wild-type plants exposed to $150 \mathrm{mM} \mathrm{NaCl}$ was approximately $27 \%$ lower $(t<0.01)$ in shoots than roots. The overexpression of PAP17 and PAP26 created significantly higher total $\mathrm{P}$ content in OE plants compared to WT plants at $150 \mathrm{mM} \mathrm{NaCl}$. In contrast, the knockout mutation of the genes resulted in significantly lower total $\mathrm{P}$ content in shoots and roots of Mu17, Mu26, and DM genotypes compared to WT plants at the same concentration (Table 4).

The evaluation of total $\mathrm{P}$ components (Pi and Po content) clearly showed that increasing $\mathrm{NaCl}$ concentrations also led to a gradual decrease in relative contents of $\mathrm{P}$ components in WT plants, as control plants (Table 4). The overexpressed and Mu26 genotypes showed the lowest and highest reduction in $\mathrm{Pi}$ and Po content in both shoots and roots compared to the wildtypes, respectively (Table 4). The overexpression and knockout mutation of PAP17 and PAP26 also caused a significant increase and decrease of $\mathrm{Pi}$ and Po content in shoots and roots of $\mathrm{OE}$ and mutant genotypes when compared to WT seedlings in $150 \mathrm{mM}$ $\mathrm{NaCl}$, respectively (Table 4). 

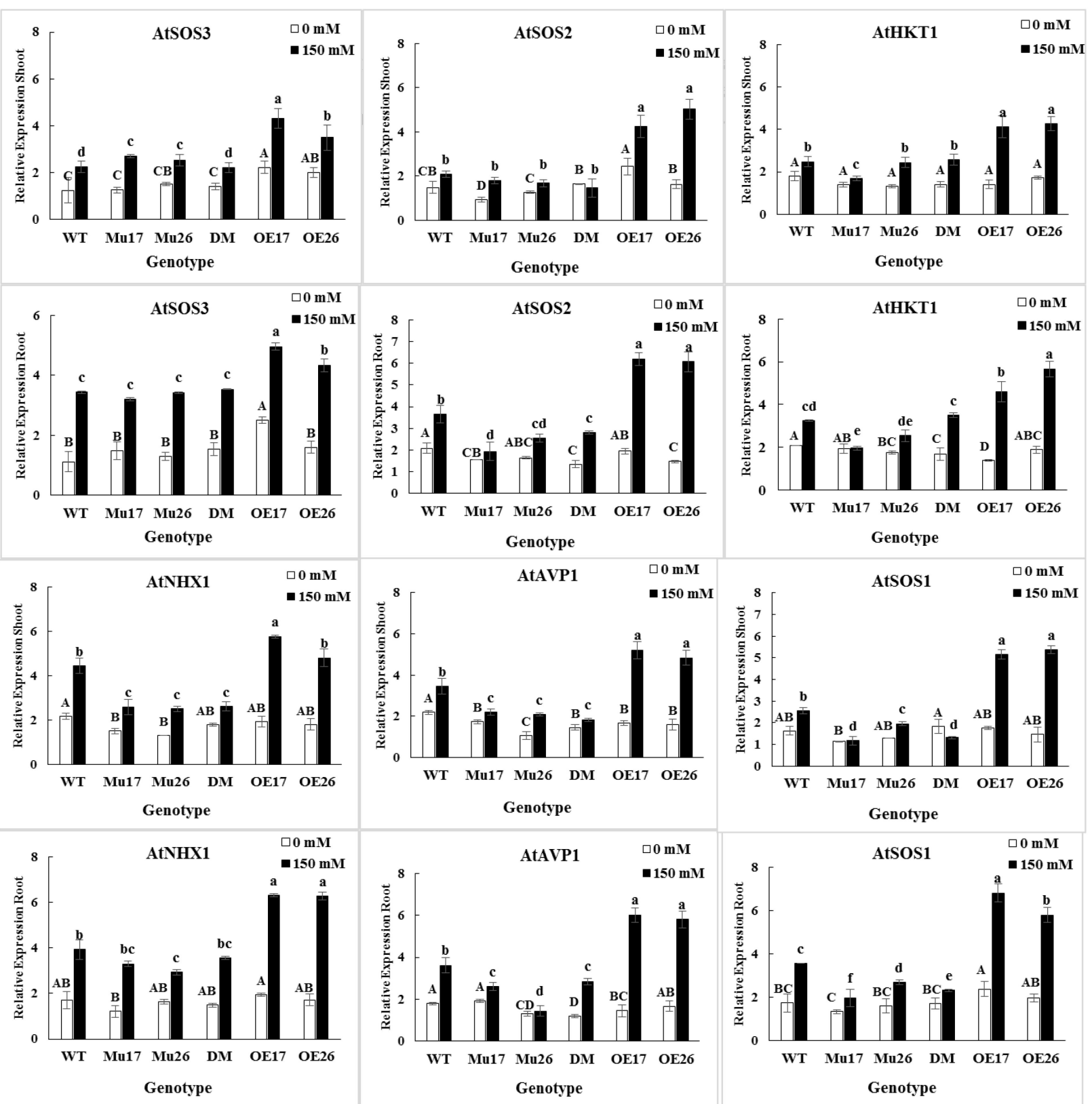

FIGURE 4 | The expression level of mentioned genes in shoots and roots of genotypes subjected to $150 \mathrm{mM} \mathrm{NaCl} \mathrm{stress} \mathrm{compared} \mathrm{to} \mathrm{no} \mathrm{NaCl} \mathrm{stress.} \mathrm{Wild-type}$ (WT), overexpress (OE), single mutant (Mu), and double mutant (DM) genotypes of Arabidopsis thaliana purple acid phosphatase 17 (AtPAP17) and 26 (AtPAP26) genes. The significant mean differences $(P<0.05)$ were separately shown at 0 and $150 \mathrm{mM} \mathrm{NaCl}$ concentrations with different uppercase and lowercase letters, respectively.

The correlation coefficient of $\mathrm{Pi}$ and total carbohydrate was $0.66(P<0.01)$ in $150 \mathrm{mM} \mathrm{NaCl}$. Still, the correlation between Pi and soluble carbohydrate in the same concentration of salt was observed to be $0.82(P<0.01)$.

\section{Phosphatase Activity}

The APase activity of wild-type plants increased 0.62-fold, 1.6fold, and 2.8-fold in the shoots as well as 0.17-fold, 0.52fold, and 1.01-fold in the roots under 50,100, and $150 \mathrm{mM}$
$\mathrm{NaCl}$, respectively, compared to the normal condition $(0 \mathrm{mM})$ (Table 4). Moreover, the increase in the APase activity of WT plants was detected to be significantly higher in the shoots $(t<0.01)$ than the roots at $150 \mathrm{mM} \mathrm{NaCl}$. In $150 \mathrm{mM}$ $\mathrm{NaCl}, \mathrm{OE} 17$ and OE26 plants showed significantly higher APase activity (shoots and roots) compared to WT plants (Table 4). The reverse results were observed for shoots and roots of Mu17, Mu26, and DM seedlings at this concentration of $\mathrm{NaCl}$ (Table 4). 
TABLE 4 | Means ( \pm SE) of the total P, free Pi, and P organic contents in genotypes subjected to the $\mathrm{NaCl}$ concentrations.

\begin{tabular}{|c|c|c|c|c|c|c|c|c|c|}
\hline & \multirow[t]{2}{*}{ Genotype } & \multicolumn{2}{|c|}{$\begin{array}{c}\text { Total P content } \\
\left(\mu \mathrm{mol} \mathrm{g}^{-1} \mathrm{DW}_{\text {plant }}{ }^{-1}\right)\end{array}$} & \multicolumn{2}{|c|}{ 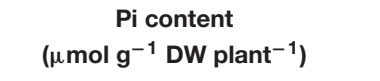 } & \multicolumn{2}{|c|}{$\begin{array}{c}\text { Po content } \\
\left(\mu \mathrm{mol} \mathrm{g}^{-1} \mathrm{DW}_{\text {plant }}{ }^{-1}\right)\end{array}$} & \multicolumn{2}{|c|}{$\begin{array}{l}\text { APase activity } \\
\text { (U } \mathrm{mg}^{-1} \text { protein) }\end{array}$} \\
\hline & & Shoot & Root & Shoot & Root & Shoot & Root & Shoot & Root \\
\hline $0 \mathrm{mM}$ & WT & $28.83 \pm 0.79^{b}$ & $36.56 \pm 1.89^{c}$ & $6.49 \pm 0.36^{\mathrm{cd}}$ & $6.71 \pm 0.66^{c}$ & $22.34 \pm 0.50^{c}$ & $29.84 \pm 2.31^{c}$ & $0.54 \pm 0.05^{\mathrm{c}}$ & $1.02 \pm 0.15^{a b}$ \\
\hline \multirow[t]{5}{*}{$\mathrm{NaCl}$} & Mu17 & $20.87 \pm 0.49^{c}$ & $27.68 \pm 2.11^{d}$ & $5.59 \pm 0.38 d^{e}$ & $6.46 \pm 0.64^{c}$ & $15.28 \pm 0.46^{d}$ & $21.22 \pm 1.91^{d}$ & $0.51 \pm 0.03^{c}$ & $0.64 \pm 0.16^{b}$ \\
\hline & Mu26 & $25.19 \pm 2.36^{\mathrm{cb}}$ & $24.96 \pm 0.71^{e}$ & $5.89 \pm 0.32^{e}$ & $4.27 \pm 0.25^{d}$ & $19.31 \pm 2.12^{\mathrm{e}}$ & $20.69 \pm 0.47^{d}$ & $0.59 \pm 0.02^{c}$ & $0.71 \pm 0.02^{b}$ \\
\hline & $\mathrm{DM}$ & $27.34 \pm 0.34^{b}$ & $22.79 \pm 1.16^{e}$ & $7.19 \pm 0.22^{\mathrm{c}}$ & $3.90 \pm 0.17^{d}$ & $20.15 \pm 0.55^{\mathrm{cd}}$ & $18.89 \pm 0.99^{d}$ & $0.76 \pm 0.08^{b}$ & $0.55 \pm 0.15^{a b}$ \\
\hline & OE17 & $42.42 \pm 3.84^{a}$ & $50.31 \pm 1.19^{a}$ & $9.52 \pm 0.78^{a}$ & $8.04 \pm 0.26^{b}$ & $32.90 \pm 1.95^{a}$ & $42.28 \pm 1.07^{a}$ & $1.55 \pm 0.01^{a}$ & $1.70 \pm 0.36^{a}$ \\
\hline & OE26 & $37.90 \pm 1.40^{a}$ & $42.67 \pm 0.89^{b}$ & $8.54 \pm 0.73^{b}$ & $9.23 \pm 0.21^{a}$ & $29.36 \pm 1.01^{b}$ & $33.44 \pm 0.69^{b}$ & $1.57 \pm 0.05^{a}$ & $1.31 \pm 0.12^{\mathrm{a}}$ \\
\hline $50 \mathrm{mM}$ & WT & $19.76 \pm 0.68^{c}$ & $22.61 \pm 0.52^{d}$ & $3.92 \pm 1.00^{\mathrm{C}}$ & $4.58 \pm 0.78^{\mathrm{cd}}$ & $15.84 \pm 0.71^{\mathrm{c}}$ & $18.03 \pm 0.91^{d}$ & $0.87 \pm 0.11^{b}$ & $1.20 \pm 0.01^{\mathrm{c}}$ \\
\hline \multirow[t]{5}{*}{$\mathrm{NaCl}$} & Mu17 & $37.73 \pm 0.12^{a}$ & $33.55 \pm 1.93^{b}$ & $9.73 \pm 0.70^{b}$ & $5.87 \pm 0.12^{c b}$ & $28.00 \pm 0.81^{a}$ & $27.68 \pm 1.94^{b}$ & $0.49 \pm 0.07^{d}$ & $1.23 \pm 0.12^{\mathrm{c}}$ \\
\hline & Mu26 & $14.39 \pm 1.92^{d}$ & $29.41 \pm 1.94^{c}$ & $4.74 \pm 0.64^{c}$ & $5.53 \pm 0.16^{c b}$ & $9.65 \pm 0.44^{e}$ & $23.88 \pm 1.87^{c}$ & $0.67 \pm 0.03^{c}$ & $0.90 \pm 0.14^{d}$ \\
\hline & DM & $17.21 \pm 1.27^{\mathrm{cd}}$ & $20.07 \pm 1.06^{e}$ & $4.65 \pm 0.43^{\mathrm{C}}$ & $3.69 \pm 0.50^{d}$ & $12.56 \pm 0.89^{d}$ & $16.38 \pm 1.42^{d}$ & $0.97 \pm 0.12^{b}$ & $1.32 \pm 0.11^{\mathrm{c}}$ \\
\hline & OE17 & $39.26 \pm 3.37^{a}$ & $52.92 \pm 2.01^{a}$ & $11.61 \pm 1.06^{a}$ & $7.02 \pm 0.91^{b}$ & $27.64 \pm 1.57^{\mathrm{a}}$ & $45.90 \pm 3.05^{a}$ & $2.19 \pm 0.0^{6 a}$ & $2.27 \pm 0.09^{a}$ \\
\hline & OE26 & $30.94 \pm 1.52^{b}$ & $33.65 \pm 0.76^{b}$ & $9.71 \pm 0.69^{b}$ & $10.36 \pm 1.23^{a}$ & $21.22 \pm 1.97^{b}$ & $22.69 \pm 2.15^{c}$ & $2.30 \pm 0.1^{2 a}$ & $1.85 \pm 0.08^{b}$ \\
\hline $100 \mathrm{mM}$ & WT & $15.50 \pm 0.61^{c}$ & $18.68 \pm 2.35^{c}$ & $3.68 \pm 0.40^{b}$ & $3.48 \pm 0.69^{b}$ & $11.82 \pm 0.95^{c}$ & $15.20 \pm 1.80^{c}$ & $1.43 \pm 0.07^{c}$ & $1.56 \pm 0.11^{\mathrm{c}}$ \\
\hline \multirow[t]{5}{*}{$\mathrm{NaCl}$} & Mu17 & $5.49 \pm 0.37^{e}$ & $15.01 \pm 3.77^{c}$ & $2.46 \pm 0.35^{c}$ & $3.70 \pm 0.30^{b}$ & $3.03 \pm 0.08^{e}$ & $11.31 \pm 1.43^{d}$ & $0.53 \pm 0.13^{e}$ & $0.80 \pm 0.05^{d}$ \\
\hline & Mu26 & $11.34 \pm 0.82^{d}$ & $17.76 \pm 0.15^{\mathrm{c}}$ & $3.23 \pm 0.20^{c b}$ & $3.29 \pm 0.29^{b}$ & $8.11 \pm 0.62^{d}$ & $14.47 \pm 0.39^{c}$ & $0.82 \pm 0.2^{d}$ & $0.57 \pm 0.11^{d}$ \\
\hline & $\mathrm{DM}$ & $11.79 \pm 0.85^{d}$ & $18.83 \pm 1.54^{c}$ & $3.21 \pm 0.27^{\mathrm{cb}}$ & $2.75 \pm 0.59^{b}$ & $8.58 \pm 0.63^{d}$ & $16.08 \pm 1.04^{c}$ & $1.08 \pm 0.22^{d}$ & $0.81 \pm 0.15^{d}$ \\
\hline & OE17 & $36.25 \pm 0.79^{a}$ & $48.17 \pm 1.85^{\mathrm{a}}$ & $7.18 \pm 0.53^{a}$ & $6.77 \pm 0.73^{a}$ & $29.07 \pm 0.42^{a}$ & $41.40 \pm 1.30^{a}$ & $2.66 \pm 0.23^{a}$ & $2.55 \pm 0.16^{b}$ \\
\hline & OE26 & $27.79 \pm 2.01^{b}$ & $29.36 \pm 1.35^{b}$ & $7.87 \pm 0.64^{a}$ & $6.78 \pm 0.79^{a}$ & $19.92 \pm 1.41^{b}$ & $22.10 \pm 2.31^{b}$ & $2.38 \pm 0.08^{b}$ & $3.13 \pm 0.30^{a}$ \\
\hline $150 \mathrm{mM}$ & WT & $9.02 \pm 1.09^{c}$ & $12.41 \pm 1.37^{c}$ & $3.23 \pm 0.11^{\mathrm{c}}$ & $2.65 \pm 0.56^{b}$ & $5.79 \pm 1.18^{\mathrm{C}}$ & $9.76 \pm 0.83^{c}$ & $2.07 \pm 0.04^{b}$ & $2.06 \pm 0.16^{c}$ \\
\hline \multirow[t]{5}{*}{$\mathrm{NaCl}$} & Mu17 & $4.84 \pm 0.51^{e d}$ & $8.94 \pm 0.36^{d}$ & $0.73 \pm 0.23^{f}$ & $0.91 \pm 0.22^{\mathrm{C}}$ & $4.10 \pm 0.28^{c d}$ & $8.03 \pm 0.25^{c}$ & $0.85 \pm 0.06^{c}$ & $1.13 \pm 0.03^{d}$ \\
\hline & Mu26 & $3.84 \pm 0.19^{\mathrm{e}}$ & $4.76 \pm 0.44^{e}$ & $1.35 \pm 0.11^{\mathrm{e}}$ & $0.98 \pm 0.07^{c}$ & $2.48 \pm 0.22^{d}$ & $3.78 \pm 0.50^{e}$ & $0.50 \pm 0.10^{d}$ & $0.59 \pm 0.01^{e}$ \\
\hline & $\mathrm{DM}$ & $5.82 \pm 0.43^{d}$ & $8.43 \pm 0.70^{d}$ & $2.09 \pm 0.19^{d}$ & $1.71 \pm 0.21^{\mathrm{c}}$ & $3.73 \pm 0.23^{d}$ & $6.72 \pm 0.59^{d}$ & $0.78 \pm 0.14^{c}$ & $0.78 \pm 0.04^{e}$ \\
\hline & OE17 & $22.18 \pm 1.32^{a}$ & $31.68 \pm 1.76^{a}$ & $4.94 \pm 0.29^{a}$ & $6.11 \pm 0.16^{a}$ & $17.24 \pm 1.61^{a}$ & $25.57 \pm 1.92^{\mathrm{a}}$ & $2.80 \pm 0.12^{\mathrm{a}}$ & $3.67 \pm 0.11^{a}$ \\
\hline & OE26 & $18.27 \pm 1.12^{b}$ & $26.12 \pm 2.18^{b}$ & $6.56 \pm 0.47^{b}$ & $5.42 \pm 0.65^{a}$ & $11.71 \pm 0.66^{b}$ & $19.75 \pm 2.66^{b}$ & $2.15 \pm 0.15^{b}$ & $3.04 \pm 0.20^{b}$ \\
\hline
\end{tabular}

For each level of $\mathrm{NaCl}$ concentration, the significant differences between means were shown with different letters at $P<0.05$.

\section{$\mathrm{NaCl}$ Stress Up-Regulates the Expression of AtPAP17 and AtPAP26 Genes}

Through severe salinity stress $(150 \mathrm{mM} \mathrm{NaCl})$, the expression level of PAP17 and PAP26 genes were strongly induced in both roots and shoots of WT plants (Figure 5). Indeed, rising $\mathrm{NaCl}$ from 0 to $150 \mathrm{mM}$ led to an increase in the PAP17 and PAP26 expression levels by 66 and $37 \%$ in shoots as well as 99 and $100 \%$ in roots of WT plants (Figure 5). When overexpressed genotypes subjected to $150 \mathrm{mM} \mathrm{NaCl}$, the expression level of PAP17 were detected to be 21 and $69 \%$ more in the shoots and roots of OE17 plants, respectively, compared to those under normal condition (Figure 5). At the same concentration of salt, the expression level of PAP26 was $51 \%$ higher in shoots and 35\% higher in roots of OE26 plants compared to the plants in normal condition. Besides, the expression level of PAP17 and PAP26 were detected to be significantly higher in both shoots and roots of OE17 and OE26 compared to wild-type plants at $150 \mathrm{mM} \mathrm{NaCl}$, respectively (Figure 5).

Further investigation showed a significant $(P<0.01)$ correlation between the expression levels of PAP17 and PAP26 genes and APase activity. The APase activity was also correlated with total, inorganic, and organic phosphate content in $150 \mathrm{mM}$ $\mathrm{NaCl}$ (Figure 6).

\section{AtPAP17 and AtPAP26 Improve Seed Yield}

To investigate the effect of AtPAP17 and AtPAP26 on seed yield, genotypes were treated with different levels of $\mathrm{NaCl}$ under in vivo condition. Our results showed that the flowering percent in double-mutant plants was significantly lower than that in wild-type plants at $150 \mathrm{mM} \mathrm{NaCl}$ (Table 5). At the beginning of the stress period, the flowering percent and pod number in DM genotype were not significantly different compared to WT seedlings at $100 \mathrm{mM} \mathrm{NaCl}$. No seeds, nevertheless, were observed in double-mutant plants at the seedling stage in pods at this condition (with more salt stress duration) (Table 5). In addition, no seeds were produced in pods of Mu26 and DM genotypes under longer salt stress duration at the highest sodium concentration (150 $\mathrm{mM} \mathrm{NaCl}$ ). The seed number per pod also was significantly lower in Mu17 and higher OE17 genotypes compared to WT plants under $150 \mathrm{mM} \mathrm{NaCl}$ condition (Table 5). Thus, no seed and 1000 seed weight were recorded in DM (at both 100 and $150 \mathrm{mM} \mathrm{NaCl}$ ) and $\mathrm{Mu} 26$ (at $150 \mathrm{mM} \mathrm{NaCl}$ ) genotypes as they could not produce any seed in high saline 


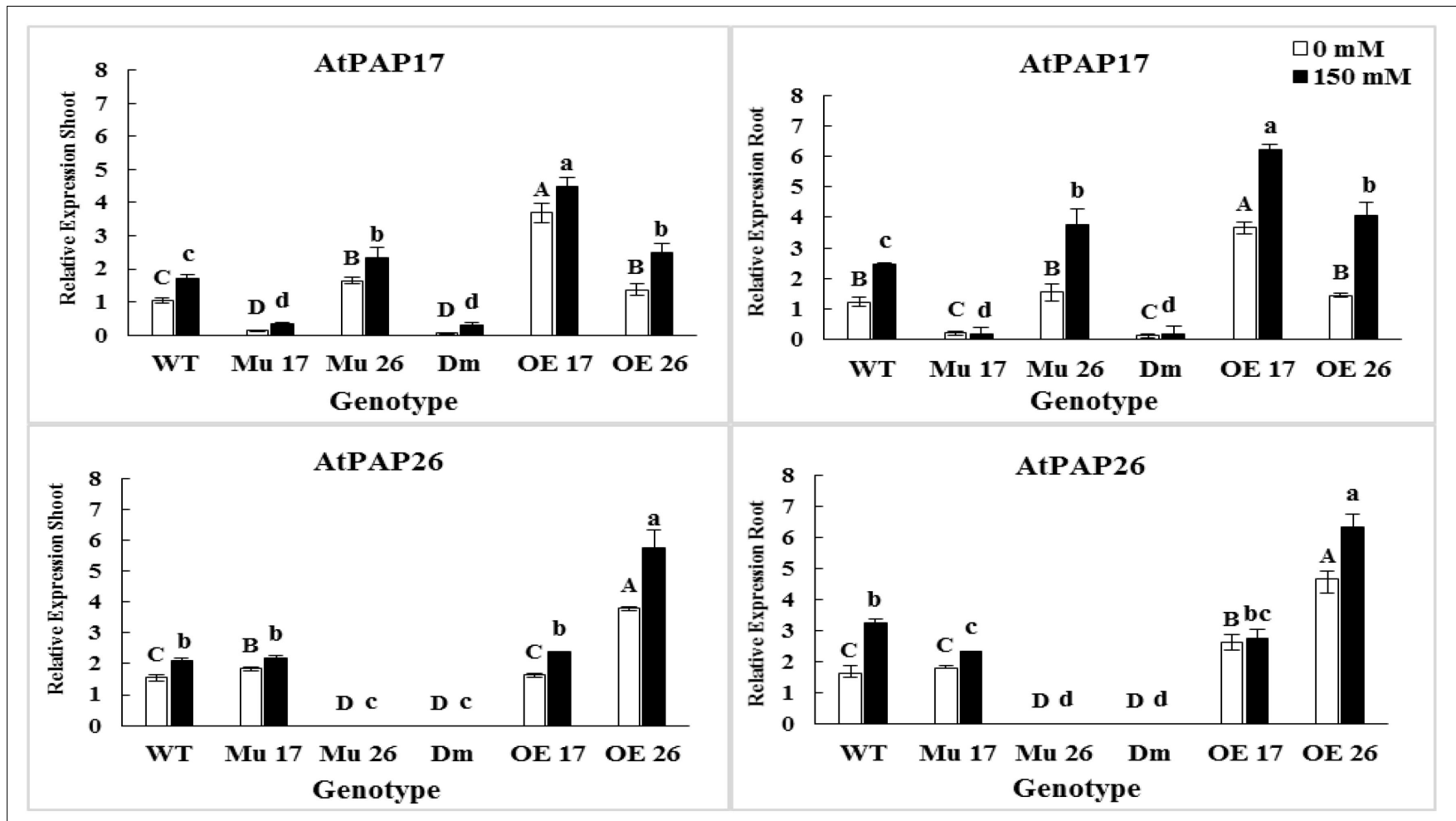

FIGURE 5 | The expression level of AtPAP17 and AtPAP26 genes in shoots and roots of genotypes subjected to $150 \mathrm{mM} \mathrm{NaCl}$ stress compared to no NaCl stress. Wild-type (WT), overexpress (OE), single mutant (Mu), and double mutant (DM) genotypes of Arabidopsis thaliana purple acid phosphatase 17 (AtPAP17) and 26 (AtPAP26) genes. The significant mean differences $(P<0.05)$ were separately shown at 0 and $150 \mathrm{mM} \mathrm{NaCl}$ concentrations with different uppercase and lowercase letters, respectively.

conditions (Table 5). However, Mu17 plants produced seeds, which had the characteristics of non-living seeds under longterm saline $(150 \mathrm{mM} \mathrm{NaCl})$ condition. In spite of these results, OE17 and OE26 genotypes showed significantly higher in 1000 seed weight compared with WT plants at the same condition (Table 5). Hence, the total seed yield of Mu17 and DM plants was significantly lower than those in the control group under $50 \mathrm{mM}$ $\mathrm{NaCl}$. Although the total seed yield of Mu17 genotype was lower than that in WT plants, the relative amount in OE17 and OE26 genotypes were significantly more as compared to that in WT plant at $100 \mathrm{mM} \mathrm{NaCl}$ (Table 5). In addition, DM genotype did not obtain any seeds under $100 \mathrm{mM} \mathrm{NaCl}$. The total seed yield of OE17 and OE26 genotypes were significantly higher than those in WT plants, whereas the seed yield was not maintained well in Mu17, Mu26, and DM genotypes at $150 \mathrm{mM} \mathrm{NaCl}$ (Table 5).

Taken together, Mu17 and Mu26 (at $150 \mathrm{mM} \mathrm{NaCl}$ ), and $\mathrm{DM}$ (at 100 and $150 \mathrm{mM} \mathrm{NaCl}$ ) did not maintain total seed yield. Despite these results, the OE17 and OE26 genotypes also produced the highest total seed yield under 100 and $150 \mathrm{mM}$ $\mathrm{NaCl}$ as well (Table 5).

\section{Complementary Analysis}

A principal component analysis (PCA) of Pearson's correlation revealed that the expression level of AtPAP17 and AtPAP26 genes associated with the activity of APX, CAT, and POX enzymes involved in reducing $\mathrm{H}_{2} \mathrm{O}_{2}$ and $\mathrm{MAD}$ accumulation in $150 \mathrm{mM} \mathrm{NaCl}$ condition (Figure 7). In the present study, the correlation between the PAP17 expression level and the activity of POX and CAT enzymes was observed to be 0.75 and $0.83(P<0.01)$, respectively. Furthermore, the correlation between PAP26 expression level with POX and CAT enzyme activities was found to be 0.49 and $0.58(P<0.05)$, respectively, at $150 \mathrm{mM} \mathrm{NaCl}$ condition (Figure 7). A high and significant positive correlation was detected between the Pi content and the expression levels of SOS3 $\left(r=0.69^{* *}\right)$, SOS2 $\left(r=0.89^{* *}\right)$, NHX1 $\left(r=0.91^{* *}\right), \operatorname{AVP1}\left(0.88^{* *}\right)$, and SOS1 $\left(0.92^{* *}\right)$ at $150 \mathrm{mM} \mathrm{NaCl}$ conditions (Figure 8). There were also significant correlations between the expression levels of SOS3 and SOS2 genes with NHX1 (0.82 and 0.90, P $<0.01), A V P 1 \quad(0.87$ and 0.96, $P<0.01$ ), and SOS1 (0.89 and 0.97, $P<0.01$ ) at the same condition (Figure 8). Furthermore, a significant correlation $\left(r=0.95^{* *}\right)$ was detected between expression levels of AVP1 and NHX1 genes at the same condition (Figure 8). The expression levels of AtPAP17 and AtPAP17 genes were closely associated with the high expression level of salt overly sensitive (SOS) pathway genes and the maintenance of a low $\mathrm{Na}^{+}$ and high $\mathrm{K}^{+}$concentrations and, consequently, a high $\mathrm{K}^{+} / \mathrm{Na}^{+}$ ratio (Figure 9).

To clarify a global overview of the effects of AtPAP17 and AtPAP26, a clustered heat map of Pearson's correlation was performed separately for all measured parameters and each genotype at normal condition and the high level of $\mathrm{NaCl}$ 


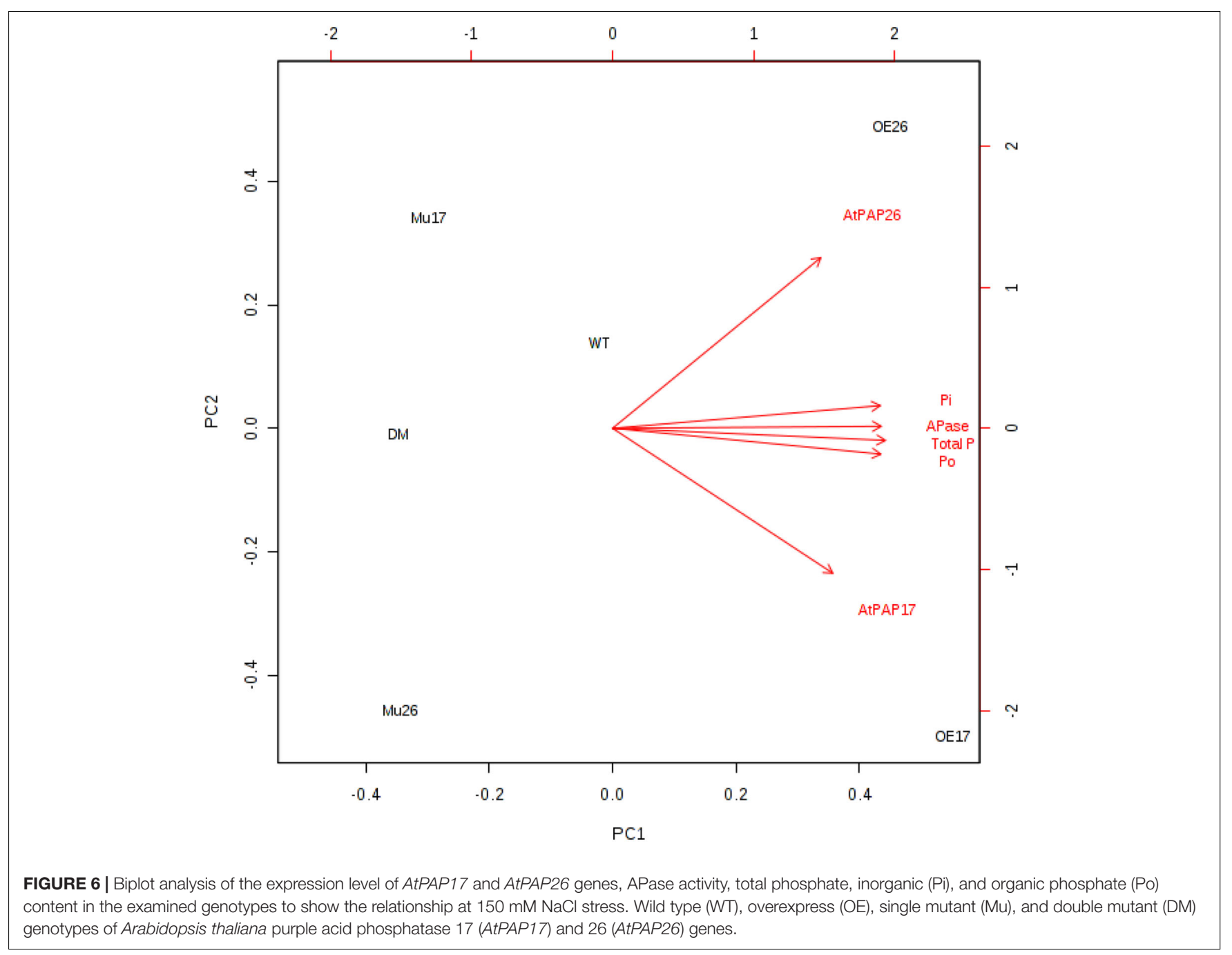

concentration as well (Figure 10). The cluster analysis showed obviously that OE17 and OE26 genotypes responded strongly to a higher level of the traits responsible for the salt-tolerance improvement and better growth, compared to WT plants. However, a lower value of these traits was observed in mutant genotypes as compared with WT ones (Figure 10). Since the genotypes presented the different effects on all measured traits, PCA with the full set of traits was performed to further assess the effect of AtPAP17 and AtPAP26 (Figure 11). According to the PCA, an obvious separation was detected among genotypes, where WT plants located between OE and mutant genotypes. Both OE17 and OE26 genotypes were clearly clustered separately with positive loading on the right side of WT, whereas the mutant genotypes were located on the left side of WT (Figure 11).

\section{DISCUSSION}

High salinity reduces the agricultural productivity of most crops intensively (Woodrow et al., 2017; Zörb et al., 2019). Salt levels that are harmful to crop growth affect large arable lands of the world (Yamaguchi and Blumwald, 2005). Hence, this makes it inevitable that the effective strategies involving in salt tolerance to alleviate the deleterious influences of salt stress, to maintain the optimum growth and yield.

Low phosphorus availability is a major constraint for photosynthesis and therefore carbohydrate production since restricts the RuBP regeneration, activation of Rubisco and other PCR cycle enzymes (such as FBPase and SBPase), carbon assimilation, and carbon partitioning (Rychter and Rao, 2005). For example, phosphorus is also one of the necessary components in the sucrose synthesis pathway (Rychter and Rao, 2005). In response, maintaining the homeostasis of phosphate is one of the well particular roles of PAPs (Del Pozo et al., 1999; Veljanovski et al., 2006; Plaxton and Tran, 2011). Therefore, the OE genotypes with more APase activity could further mediate the phosphate homeostasis, which resulted in enhancing the carbohydrate content and the related trends in salt stress conditions.

Plant physiological responses to water deficit stress induce osmotic adjustment to maintain current water uptake and cell turgor (Chaves et al., 2009). OE genotypes were more effective in the enhancement of proline and glycine betaine 
TABLE 5 | Means ( \pm SE) of the yield and yield components in genotypes subjected to the $\mathrm{NaCl}$ concentrations.

\begin{tabular}{|c|c|c|c|c|c|c|}
\hline & Genotype & Flowering \% & Number of pods plant ${ }^{-1}$ & Number of seed pods ${ }^{-1}$ & 1000 seed weight $(\mathrm{mg})$ & Total seed yield $\left(\mathrm{mg} \mathrm{plant}^{-1}\right)$ \\
\hline $0 \mathrm{mM}$ & WT & $65.04 \pm 5.1^{b}$ & $6.44 \pm 1.3^{\mathrm{a}}$ & $36.00 \pm 0.6^{b}$ & $17.00 \pm 0.2^{b}$ & $3.92 \pm 0.8^{a b}$ \\
\hline \multirow[t]{5}{*}{$\mathrm{NaCl}$} & Mu17 & $25.95 \pm 1.0^{\mathrm{C}}$ & $2.66 \pm 0.2^{b}$ & $35.00 \pm 1.7^{b}$ & $15.73 \pm 0.5^{c}$ & $3.47 \pm 0.1^{b}$ \\
\hline & Mu26 & $61.62 \pm 3.6^{b}$ & $6.51 \pm 0.3^{a}$ & $34.67 \pm 1.2^{\mathrm{b}}$ & $16.40 \pm 0.1^{b}$ & $3.70 \pm 0.2^{a b}$ \\
\hline & $\mathrm{DM}$ & $71.11 \pm 4.4^{b}$ & $8.78 \pm 0.9^{a}$ & $36.33 \pm 0.3^{b}$ & $15.20 \pm 0.1^{c}$ & $4.86 \pm 0.5^{a b}$ \\
\hline & OE17 & $94.44 \pm 5.5^{a}$ & $8.42 \pm 1.2^{\mathrm{a}}$ & $40.67 \pm 1.2^{\mathrm{a}}$ & $18.07 \pm 0.4^{a}$ & $5.27 \pm 0.6^{a}$ \\
\hline & OE26 & $76.67 \pm 6.7^{b}$ & $7.89 \pm 0.4^{a}$ & $33.33 \pm 0.7^{b}$ & $18.07 \pm 0.2^{\mathrm{a}}$ & $4.77 \pm 0.3^{a b}$ \\
\hline $50 \mathrm{mM}$ & WT & $51.19 \pm 1.9^{b}$ & $6.70 \pm 1.1^{a}$ & $32.00 \pm 1.5^{b}$ & $15.67 \pm 0.2^{b}$ & $3.32 \pm 0.4^{a}$ \\
\hline \multirow[t]{5}{*}{$\mathrm{NaCl}$} & Mu17 & $74.60 \pm 12.9^{a b}$ & $3.47 \pm 0.8^{b}$ & $17.67 \pm 1.4^{\mathrm{c}}$ & $11.93 \pm 0.8^{c}$ & $0.71 \pm 0.1^{b}$ \\
\hline & Mu26 & $75.84 \pm 7.3^{b}$ & $5.71 \pm 0.6^{a b}$ & $28.00 \pm 1.5^{\mathrm{b}}$ & $13.00 \pm 0.3^{c}$ & $2.10 \pm 0.3^{a b}$ \\
\hline & $\mathrm{DM}$ & $81.57 \pm 4.2^{b}$ & $6.01 \pm 0.8^{a b}$ & $21.00 \pm 1.0^{\mathrm{C}}$ & $9.00 \pm 0.2^{d}$ & $1.12 \pm 0.1^{b}$ \\
\hline & OE17 & $90.58 \pm 1.2^{b}$ & $5.81 \pm 1.1^{a b}$ & $36.67 \pm 1.2^{a}$ & $17.13 \pm 0.8^{a}$ & $3.69 \pm 0.8^{a}$ \\
\hline & OE26 & $88.64 \pm 7.3^{b}$ & $6.59 \pm 0.8^{a}$ & $38.33 \pm 0.7^{a}$ & $15.13 \pm 0.5^{b}$ & $2.90 \pm 0.8^{a}$ \\
\hline $100 \mathrm{mM}$ & WT & $81.82 \pm 2.0^{a b}$ & $4.27 \pm 0.5^{b}$ & $28.33 \pm 3.5^{b}$ & $12.06 \pm 1.8^{b}$ & $1.45 \pm 0.3^{c}$ \\
\hline \multirow[t]{5}{*}{$\mathrm{NaCl}$} & Mu17 & $71.14 \pm 5.3^{b}$ & $4.35 \pm 0.3^{b}$ & $22.33 \pm 1.4^{c}$ & $9.733 \pm 0.3^{b}$ & $0.94 \pm 0.1^{d}$ \\
\hline & Mu26 & $71.15 \pm 4.5^{b}$ & $6.75 \pm 0.4^{a}$ & $25.67 \pm 0.3 b^{c}$ & $11.40 \pm 0.4^{b}$ & $1.73 \pm 0.0^{\mathrm{bc}}$ \\
\hline & $\mathrm{DM}$ & $70.85 \pm 7.9^{b}$ & $5.01 \pm 0.6^{b}$ & $0.00 \pm 0.0^{d}$ & $0.00 \pm 0.0^{c}$ & $0.00 \pm 0.0^{e}$ \\
\hline & OE17 & $90.11 \pm 5.0^{a}$ & $4.12 \pm 0.2^{b}$ & $26.67 \pm 0.3^{b c}$ & $15.26 \pm 0.2^{a}$ & $2.14 \pm 0.1^{a b}$ \\
\hline & OE26 & $69.80 \pm 1.6^{b}$ & $5.33 \pm 0.3^{b}$ & $34.33 \pm 0.7^{a}$ & $12.00 \pm 0.4^{b}$ & $2.19 \pm 0.1^{a}$ \\
\hline $150 \mathrm{mM}$ & WT & $54.44 \pm 10.9^{a}$ & $3.23 \pm 0.4^{b c}$ & $21.33 \pm 2.1^{b}$ & $9.60 \pm 0.3^{c}$ & $0.67 \pm 0.1^{c}$ \\
\hline \multirow[t]{5}{*}{$\mathrm{NaCl}$} & Mu17 & $47.59 \pm 5.5^{a b}$ & $3.05 \pm 0.3^{c}$ & $10.00 \pm 0.0^{c}$ & $0.00 \pm 0.0^{d}$ & $0.00 \pm 0.0^{d}$ \\
\hline & Mu26 & $60.32 \pm 5.2^{\mathrm{a}}$ & $4.50 \pm 0.4^{a}$ & $0.00 \pm 0.0^{d}$ & $0.00 \pm 0.0^{d}$ & $0.00 \pm 0.0^{d}$ \\
\hline & $\mathrm{DM}$ & $33.12 \pm 12.0^{b}$ & $2.52 \pm 0.2^{c}$ & $0.00 \pm 0.0^{d}$ & $0.00 \pm 0.0^{d}$ & $0.00 \pm 0.0^{d}$ \\
\hline & OE17 & $64.50 \pm 4.5^{a}$ & $3.90 \pm 0.2^{a b}$ & $31.67 \pm 1.2^{\mathrm{a}}$ & $14.33 \pm 1.0^{\mathrm{a}}$ & $1.88 \pm 0.2^{a}$ \\
\hline & OE26 & $65.48 \pm 3.0^{\mathrm{a}}$ & $3.22 \pm 0.2^{\mathrm{bc}}$ & $22.67 \pm 0.3^{b}$ & $11.53 \pm 0.6^{b}$ & $1.27 \pm 0.1^{b}$ \\
\hline
\end{tabular}

For each level of $\mathrm{NaCl}$ concentration, the significant differences between means were shown with different letters at $P<0.05$.

accumulation in plants under high concentrations of $\mathrm{NaCl}$, which can increase osmotic pressure, and mutant genotypes were the least effective plants in this way. Although glycine betaine and proline are kinds of well-studied compatible solutes, the effect of phosphorus on their production is still unknown. Despite this, according to pathways of proline and synthesis (Lehmann et al., 2010; Meena et al., 2019), which depend on phosphate, we hypothesize that there is a relationship between phosphate supply and the metabolic pathway. Several studies showed that quite a few factors could play multifunctional roles in adaptation to salt tolerance with increasing the activity of antioxidant enzymes, the accumulation of proline and glycine betaine, and so on. For example, supplementation of acetylcholine (ACh), jasmonic acid, nitric oxide, and salicylic acid ameliorated the negative influences of salt stress on plant growth (Ahanger and Agarwal, 2017; Ahmad et al., 2018a,b; Ahanger et al., 2020; Qin et al., 2020).

Oxidative stress, as a secondary effect of salt stress, causes damage to macromolecules such as lipid, protein, and DNA. Plant cells respond to oxidative stress by increasing enzymatic and non-enzymatic antioxidant activity (Ahmad et al., 2019). Since the AtPAP17 and AtPAP26 genes via enzymatic antioxidant activity involve in the metabolism of ROS (Del Pozo et al., 1999; Veljanovski et al., 2006), overexpression of which led to the highest enzymatic antioxidant activity, and consequently, the lowest amount of $\mathrm{H}_{2} \mathrm{O}_{2}$ as well as MDA in OE17 and OE26 plants, under high-salinity treatment (150 mM NaCl) (Table 3 and Figure 7). Conversely, the knockout mutation of these genes resulted in the lowest enzymatic antioxidant activity and, thus, the most amount of $\mathrm{H}_{2} \mathrm{O}_{2}$ and MDA amount in mutant plants at the same conditions (Table 3 and Figure 7). Numerous studies have shown a correlation between up-regulation of specific enzymatic antioxidant activities and tolerance to abiotic stresses, including salinity (Bartels and Sunkar, 2005; Hanin et al., 2016; Ahmad et al., 2019). Therefore, the raise of the enzymatic antioxidant activities in $\mathrm{OE}$ genotypes positively correlated with improving the parameters affecting the plant growth. Improving the management of ROS and decreasing cell damages in OE17 and OE26 plants could be referenced as an important biological basis for better plant growth features, as well as increasing the biomass, yield components, and total yield, under salt conditions (Figure 10).

Regarding the acid phosphatase (APase) functions, having perceived salinity signal by plant cells, the ultimate biochemical and molecular responses depend on the signaling molecules involved in the activation of signaling pathways, which are able to enhance plant ability to salinity tolerance (Hanin et al., 2016; Isayenkov and Maathuis, 2019; Zhao et al., 2020). Protein phosphatases and protein kinases that catalyze reversible phosphorylation are of utmost importance in signal transduction and regulating metabolic activities as well. Indeed, phosphatases, as the obligate partners of kinases, are half of a 


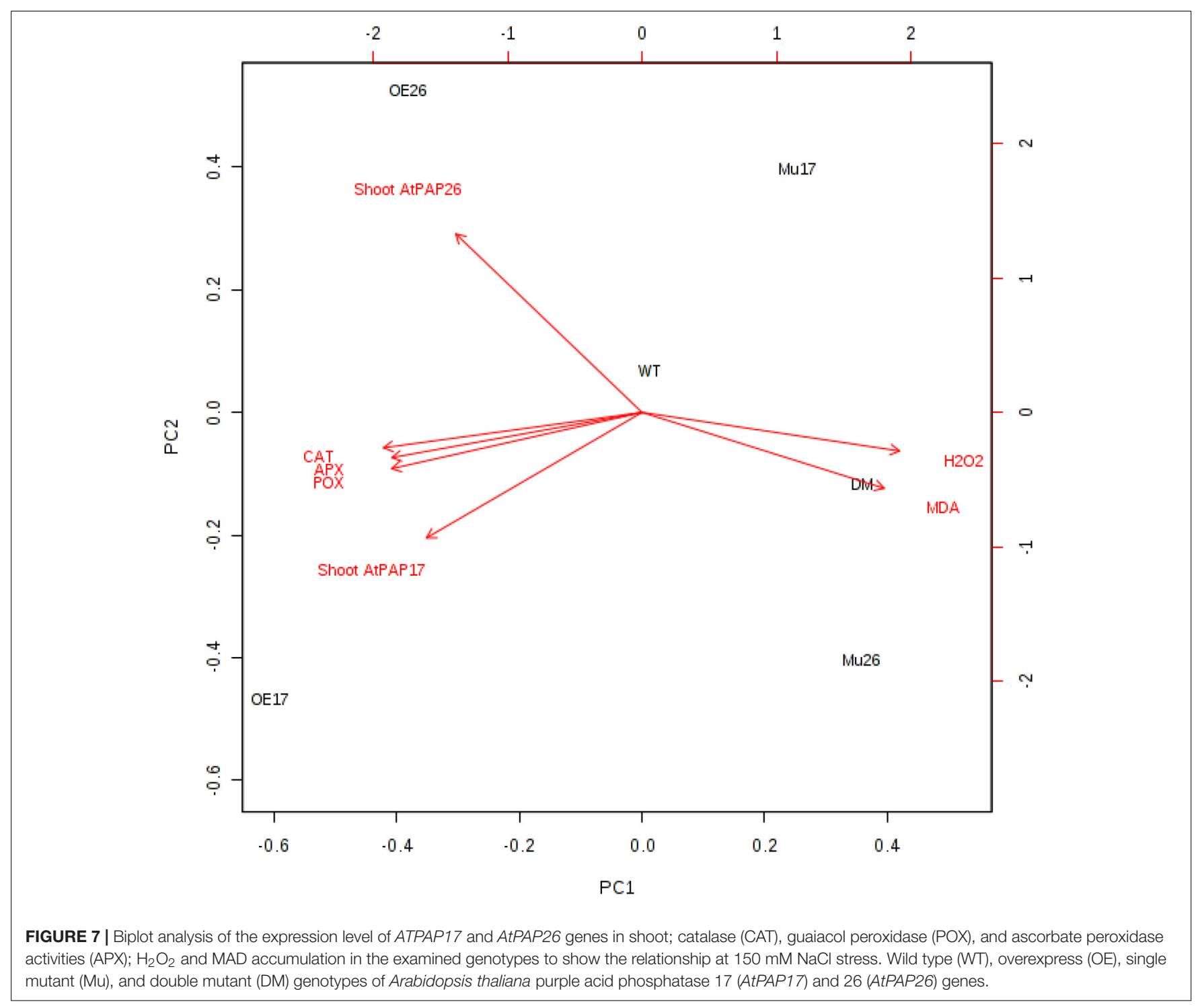

phosphorylation/dephosphorylation switch, which have a critical role in the signaling pathways (DeLong, 2006). The regulation of ABA signaling, for example, in plant guard cells is mediated by a protein kinase-phosphatase pair, which interacts with an ion channel to regulate stomatal movements (Lee et al., 2009). To give another example, a $\mathrm{Ca}^{2+} /$ calmodulin-dependent protein phosphatase mediates a salt-stress signal transduction pathway that influences salt tolerance via the regulation of sodium influx and efflux (Pardo et al., 1998).

Considerably, the maintenance of low $\mathrm{Na}^{+}$and high $\mathrm{K}^{+}$ concentrations in plant tissues is the most effective strategy to tolerate high levels of salinity. In fact, the high $\mathrm{K}^{+} / \mathrm{Na}^{+}$ ratio is very important for many species to maintain a low concentration of $\mathrm{Na}^{+}$(Tester and Davenport, 2003; Deinlein et al., 2014). Also in the current study, the correlation between $\mathrm{K}^{+} / \mathrm{Na}^{+}$ratio and dry weight of the seedling (0.94) was strongly higher than the correlation between $\mathrm{Na}^{+}$content and seedling dry weight $(0.82)$. the pieces of evidence show that $\mathrm{K}^{+}$ion activates more than 50 enzymes and requires for protein synthesis as well as many physiological and biological processes, while $\mathrm{Na}^{+}$ion cannot substitute for this role (Tester and Davenport, 2003; Isayenkov and Maathuis, 2019). Metabolic toxicity of $\mathrm{Na}^{+}$ is drastically a result of its ability to compete with $\mathrm{K}^{+}$for the occupation of binding sites essential for cellular functions (Tester and Davenport, 2003). Thus, the high level of $\mathrm{Na}^{+}$or low $\mathrm{K}^{+} / \mathrm{Na}^{+}$ratios more likely could disrupt various enzymatic processes in Mu17, Mu26, and DM cytoplasm. These results were supported by the overexpression of PAP17 and PAP26 that caused the low sensitivity in OE17 and OE26 plants with high salt stress (Figure 10). The alteration of the biomass, yield components, and total yield among genotypes studied (at $150 \mathrm{mM} \mathrm{NaCl}$ ) obviously confirmed that the $\mathrm{K}^{+} / \mathrm{Na}^{+}$balance will be the downstream effect of PAP17 and PAP26 in high salt stress (Figure 10).

The SOS pathway has a critical role in establishing ion homeostasis, and consequently, plant adaptation to salt stress (Ji et al., 2013). At the beginning of this pathway, 


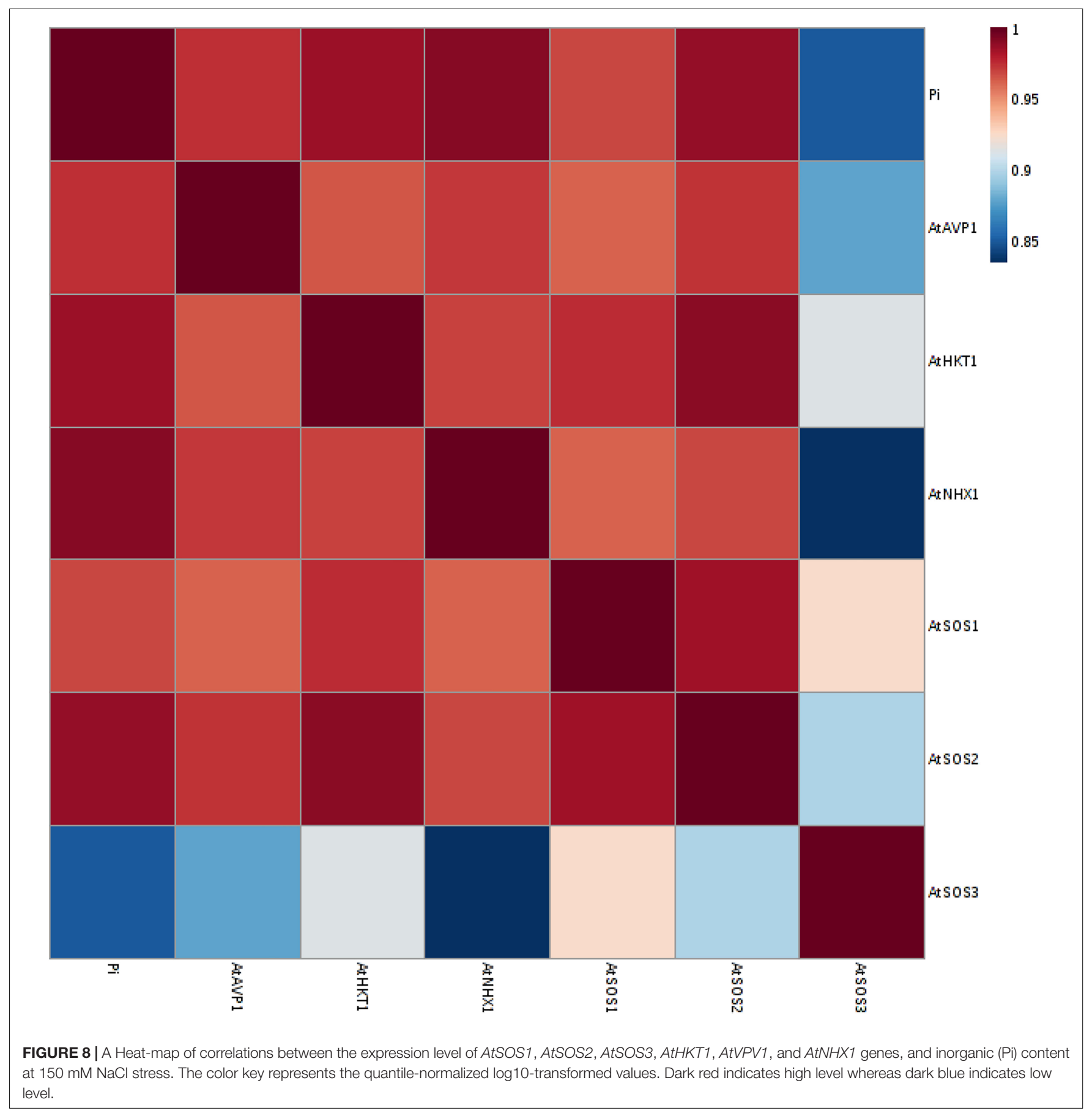

SOS3, a myristoylated calcium-binding protein, senses increasing in salinity-induced cytosolic $\mathrm{Ca}^{2+}$. For more explanation, the concentration of $\mathrm{Ca}^{2+}$ and inositol 1,4,5trisphosphate (IP3) in the cytosol increased by $\mathrm{NaCl}$ stress. The increase in IP3 concentration, which hydrolyzes through phosphatidylinositol 4,5-bisphosphate (PIP2), also mediates cellular $\mathrm{Ca}^{2+}$ mobilization. The translocation of cytosolic calcium mediates through $\mathrm{Ca}^{2+}$ channels and pumps depending on ATPase activity, which are presented on the membranes (Park et al., 2016). According to our results, the enhanced capacity of APase activity and phosphate availability in overexpress genotypes can improve the influx and release $\mathrm{Ca}^{2+}$, and consequently enhance SOS3 expression in OE17 and OE26 plants at high salt stress. The relationship between the $\mathrm{Pi}$ content and SOS3 expression level strongly supported this conclusion (Figure 8). Then, the activated SOS3 protein physically interacts with the auto-inhibitory domain of SOS2, which form the SOS2/SOS3 complex. The kinase complex phosphorylates and regulates other genes: NHX1, AVP1, and SOS1, to prevent the excess $\mathrm{Na}^{+}$accumulation in the plant 


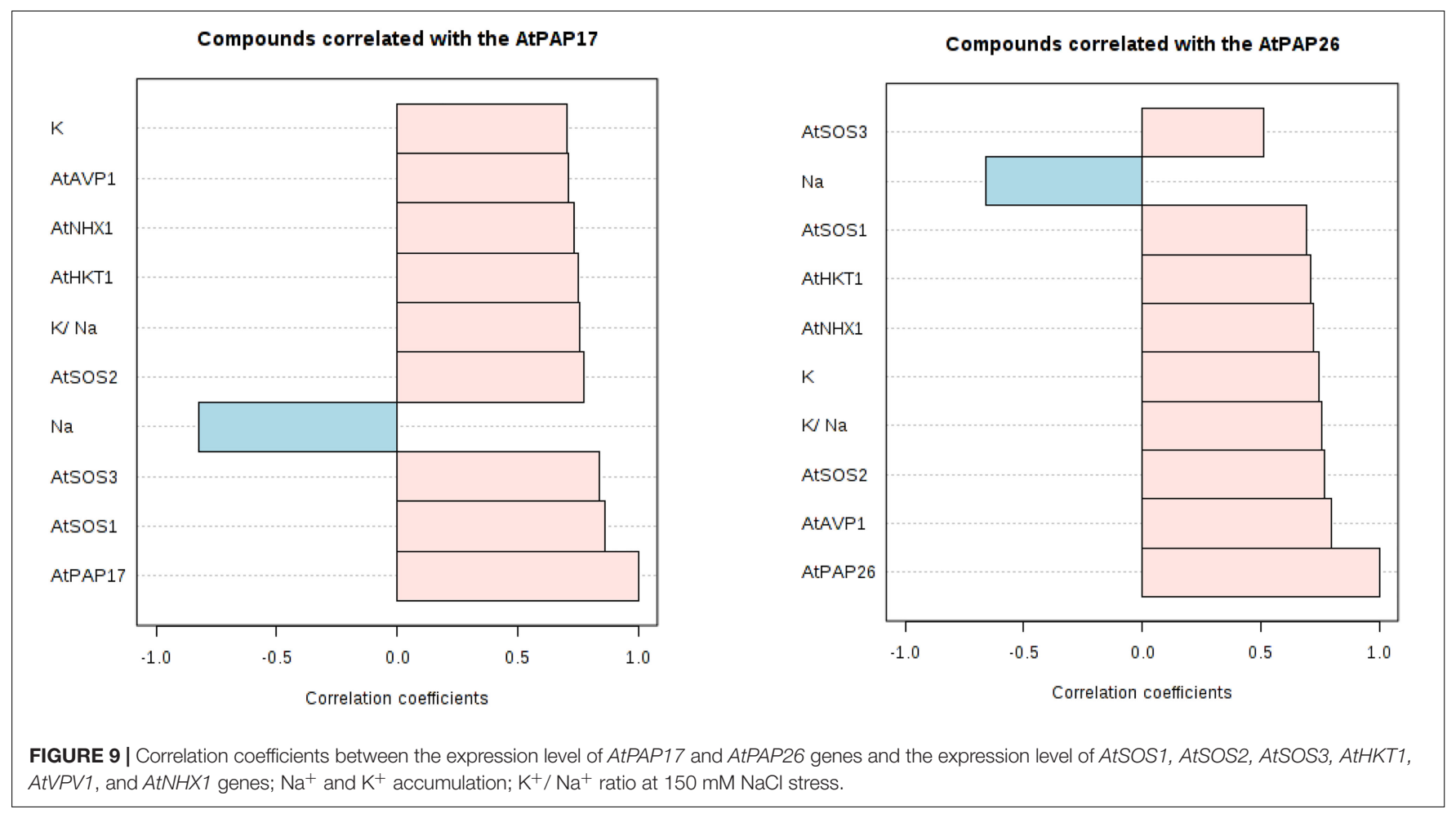

cymplast (Hanin et al., 2016; Isayenkov and Maathuis, 2019; Zhao et al., 2020). Due to the nature of serine/threonine protein kinase SOS2, the activity of which dependents on phosphate concentration intensively. Here, a significant positive $(P<0.05)$ correlation was observed between the expression level SOS2 and SOS3 as well as the Pi content and SOS2 expression level at $150 \mathrm{mM} \mathrm{NaCl}$ (Figure 8). Therefore, OE17 and OE26 genotypes with a better ability of phosphate homeostasis in plant cells exhibited significantly higher SOS2 expression.

Sodium compartmentation into vacuoles is another plant strategy for maintaining the lower ion concentration and minimizing the deleterious effects of excess $\mathrm{Na}^{+}$in the cytosol. The NHX1, as a vacuolar $\mathrm{Na}^{+} / \mathrm{H}^{+}$transporter, plays a critical role in sequestering $\mathrm{Na}^{+}$into the vacuole (Liang et al., 2015; Park et al., 2016). Hence, genotypes with higher expression and activity of NHX1 would be more successful in stress conditions. Here, the highest NHX1 expression level belonged to the overexpressed genotypes, both in shoot and root tissues of OE17, and shoot of OE26 genotype. Since SOS2/SOS3 kinase complex phosphorylates and activates the vacuolar $\mathrm{Na}^{+} / \mathrm{H}^{+}$ transporter in the cells, the enhanced SOS2 expression levels in the overexpressed genotypes led to an increase in NHX1 expression level (Figure 8). The inverse results were obviously observed for the mutant genotypes, as NHX1 expression decreased significantly in the shoots of three mutant genotypes and $\mathrm{Mu} 26$ roots compared to that in WT ones (Figure 4).

The vacuolar $\mathrm{Na}^{+} / \mathrm{H}^{+}$antiporter is driven by an electrochemical gradient of protons across the tonoplast that can be generated by vacuolar $\mathrm{H}^{+}$-pumps, $\mathrm{H}^{+}$-ATPase, or $\mathrm{H}^{+}$-pyrophosphatase $\left(\mathrm{H}^{+}\right.$-PPase $)$type. AVP1 is a vacuolar
$\mathrm{H}^{+}$-PPase that acidifies vacuoles in plant cells (Maeshima, 2000; Zhao et al., 2020). The results showed that OE17 and OE26 plants with higher levels of SOS2 and SOS3 expression and more PPi availability in the plant cells could be likely more efficient in enhanced activity and expression of AVP1 at high salt stress (Figure 9 and Table 4). We also suggest that the increased AVP1 expression level in OE17 and OE26 plants provided an additional driving force for vacuolar sodium accumulation via the vacuolar $\mathrm{Na}^{+} / \mathrm{H}^{+}$antiporter, NHX1 (Figures 8, 9). These results were also confirmed by mutant genotypes, in which the AVP1 expression level significantly decreased both in shoot and root tissues of all three mutant genotypes compared to WT plants at the same condition. Further, this is obviously verified by the correlation between the NHX1 expression level and SOS3 and SOS2 expressions as well as the relationship between the Pi content and NHX1 expression level (Figure 8). Besides, the compartmentation of $\mathrm{Na}^{+}$could maintain the turgor of transgenic plants, since increase in cellular solute content might lead to an increase in the uptake of water (Gaxiola et al., 2001). Our findings of changes in the proline and glycine betaine potential in the shoots and roots of genotypes studied at high salt stress condition (Table 3) are consistent with this idea.

SOS2/SOS3 kinase complex also associates with SOS1 transporter phosphorylation in the plasma membrane and activating $\mathrm{Na}^{+}$efflux from the cytosol to apoplast (KatiyarAgarwal et al., 2006; Ji et al., 2013). This antiporter is powered by the operation of the plasma membrane $\mathrm{H}^{+}$-ATPase that definitely associates with available phosphate. Therefore, according to these pieces of evidence and more APase activity of OE genotypes, we 


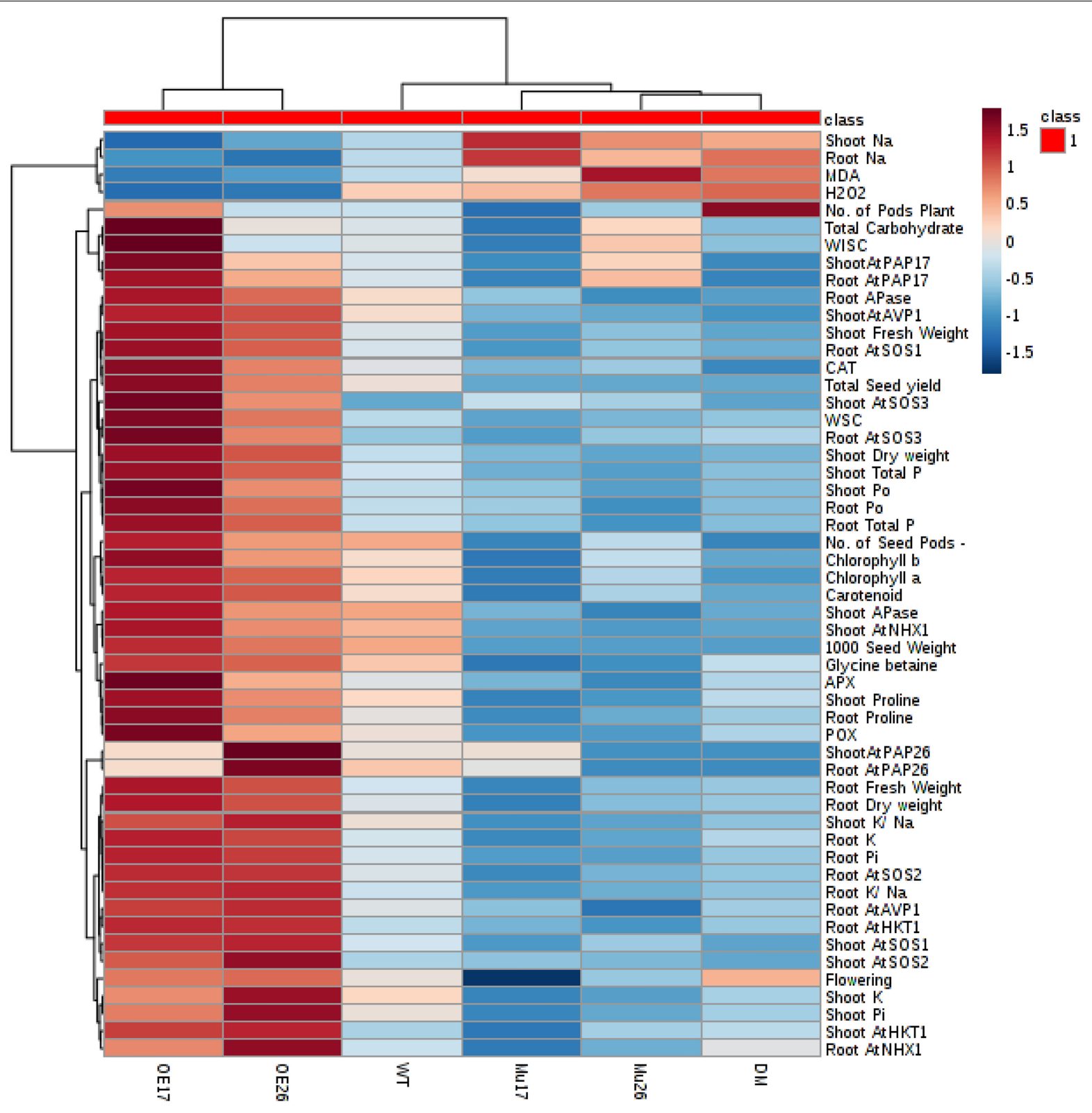

FIGURE 10 | A heat map of the impact of overexpression and knockout of AtPAP17 and AtPAP26 genes on the molecular, physiological, biochemical, and morphological parameters of the studied genotypes at $150 \mathrm{mM} \mathrm{NaCl}$ stress. Wild-type (WT), overexpress (OE), single mutant (Mu), and double mutant (DM) genotypes of Arabidopsis thaliana purple acid phosphatase 17 (AtPAP17) and 26 (AtPAP26) genes. The color key represents the quantile-normalized

log10-transformed values. Dark red indicates high level whereas dark blue indicates low level.

propose that the rising in SOS2/SOS3 kinase complex activity and plasma membrane $\mathrm{H}^{+}$-ATPase was desirable for increasing antiporter SOS1 activity in OE17 and OE26 genotypes. The result provides a feasible way to improve SOS1 expression level. Shi et al. (2000) have reported that the expression level of SOS1 in plants is up-regulated in response to $\mathrm{NaCl}$ stress and this upregulation is also abated in SOS3 or SOS2 mutant plants. The relationship between SOS1 expression and the SOS3 and SOS2 expression levels and the $\mathrm{Pi}$ content confirmed the mentioned results (Figure 8).
To deal with $\mathrm{Na}^{+}$-specific toxicity in the cytosol, plant cells also restrict $\mathrm{Na}^{+}$influx. The HKT1 gene is a selective $\mathrm{Na}^{+}$ transporter that mediates $\mathrm{K}^{+}$transport as well. In fact, HKT1type transporters are responsible for the balance between $\mathrm{Na}^{+}$ and $\mathrm{K}^{+}$ions under salinity stress (Yokoi et al., 2002; Ali et al., 2019). Increased levels of HKT1 gene expression in OE plants might indicate increased $\mathrm{Na}^{+}$uptake into the cells. However, other roles of HKT1 in various tissues can shed more light on this hurried conclusion including the $\mathrm{Na}^{+}$loading regulation into the root xylem, $\mathrm{Na}^{+}$loading into the phloem sap in shoot, and 


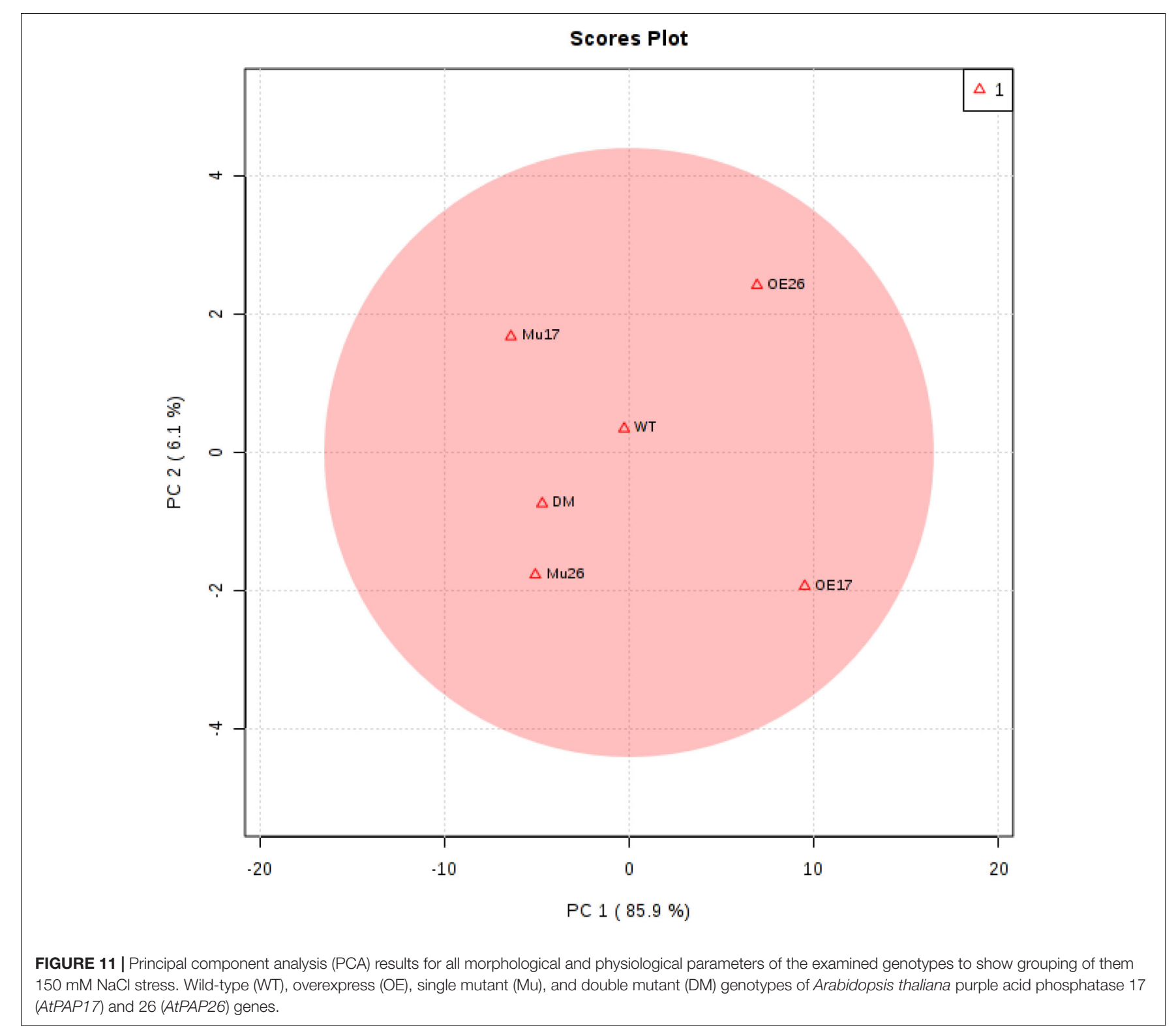

limiting $\mathrm{Na}^{+}$influx to root (Chinnusamy et al., 2006; Munns and Tester, 2008; Hasegawa, 2013; Ali et al., 2019). The high $\mathrm{K}^{+} / \mathrm{Na}^{+}$ratio in OE17 and OE26 plants provided evidence for the hypothesis that up-regulation of HKT1 gene led to the regulation of $\mathrm{Na}^{+}$and $\mathrm{K}^{+}$homeostasis under salinity stress. maintaining a high $\mathrm{K}^{+} / \mathrm{Na}^{+}$ratio in the cytosol is critical for the function of cells, especially under high-salinity condition (Deinlein et al., 2014; Zhao et al., 2020).

The high expression level of SOS pathway genes and their relationship with the maintenance of a high $\mathrm{K}^{+} / \mathrm{Na}^{+}$rate could be considered for future salinity tolerance in $\mathrm{OE}$ genotypes (Figure 9). In addition, maintaining a high $\mathrm{K}^{+} / \mathrm{Na}^{+}$ratio could have a relevant role in conferring tolerance to stress combination, both as a low destructive effect on plant cells and as a regulatory effect in the protection of cell lipid, proteins, and DNA damages from oxidative processes. The changes observed in $\mathrm{H}_{2} \mathrm{O}_{2}$ and
MDA content of the leaves in different genotypes (Table 3) can also demonstrate the interaction between SOS1 and RCD1 (radical-induced cell death), which is a transcriptional regulator of ROS homeostasis (Katiyar-Agarwal et al., 2006).

All these properties of OE17 and OE26 plants can be helpful in establishing lower $\mathrm{Na}^{+}$concentration in the cytosol (Figure 9). This situation largely accomplished through PAP17 and PAP26 roles in more cytosolic $\mathrm{Na}^{+}$transportation into the vacuole and apoplast space, consequently, alleviating the $\mathrm{Na}^{+}$toxic effects. These results were closely associated with the photosynthetic pigments and total carbohydrate content, hence, the higher photosynthesis capacity indicated in OE17 and OE26 compared to those in WT plants (Table 2). These conclusions were supported by investigation of the studied characteristics in Mu17, Mu26, and DM plants. Therefore, these results can introduce such an important and basic strategy to improve the growth 
and yield features of plants, since the living cells need strategies to protect them from the $\mathrm{Na}^{+}$ion damage, under salt stress condition (Xu et al., 2011).

Concerning plants' phosphate, the results revealed that the salt stress decreases the phosphate content and increases the APase activity in plants, which were in agreement with previous reports (Martinez and Lächli, 1991; Martinez and Läuchli, 1994; Navarro et al., 2001; Parida and Das, 2005; Brown et al., 2006) who reported the acquisition and utilization of $\mathrm{Pi}$ are decreased in plants under salt stress. Induction of APase activity is one of the essential indicators of plant response to $\mathrm{Pi}$ starvation (Abel et al., 2002; Yuan and Liu, 2008; Tran et al., 2010a). The expression of both PAP17 and PAP26 genes also was strongly induced by high salt stress $(150 \mathrm{mM} \mathrm{NaCl})$, and the expression levels closely correlated with the APase activity (Figure 6). These results are in agreement with previous studies, documenting the constitutive expression of PAP17 and PAP26 transcripts under high salt stress in Arabidopsis (Del Pozo et al., 1999; Lohrasebi et al., 2007).

At high salt stress, overexpression of PAP17 and PAP26 could result in increasing intracellular APase activity in both $\mathrm{OE}$ genotypes, where exhibited significant increases in the total $\mathrm{P}$ content, $\mathrm{Pi}$, and $\mathrm{Po}$ content as compared to WT plants. These results were closely associated with the improved physiological, biochemical, and molecular responses to boost salt tolerance (Figures 10, 11). Improving all these characteristics would be beneficial for higher photosynthesis capacity and, ultimately, more efficient in growth of OE17 and OE26 plants (Figures 10,11). Our measurements of the studied characteristics are supported by loss of PAP17 and PAP26 function in mutant genotypes (Mu17, Mu26, and DM) that showed sensitivity to high salt stress (Figures 10, 11). Several studies have reported that overexpression of secreted PAPs can improve $P$ accumulation and plant biomass (Xiao et al., 2006; Hur et al., 2007; Ma et al., 2009; Wang et al., 2009).

The extra $\mathrm{Pi}$, which was released and accumulated in the cell by overexertion of AtPAP26, may be the possible reason that more significant APase activity was not detected in OE26 shoots compared to WT shoots at $150 \mathrm{mM} \mathrm{NaCl}$. Previous studies had indicated that AtPAP26 is a major intracellular and secreted APase as well (Veljanovski et al., 2006; Hurley et al., 2010; Tran et al., 2010b). This hypothesis is confirmed by comparing the Pi content of shoots between OE26 and WT plants, even comparing with OE17 shoots at $150 \mathrm{mM} \mathrm{NaCl}$. Indeed, Pi content of OE26 shoots was 1.03-fold, and 0.33-fold more compared to that in WT and OE17 shoots, respectively, at the same condition (Table 4).

At first glance, it is difficult to believe that MU26 or DM plants grown at 0 or $50 \mathrm{mM} \mathrm{NaCl}$ presented a similar or greater shoot APase activity as compared with that in WT plants. Nonetheless, similar results have been obtained by Veljanovski et al. (2006); Hurley et al. (2010), and Farhadi et al. (2020) who reported that the elimination of a member of the AtPAP family could simultaneously exert a significant stimulating effect on nonspecific APase activity and growth of lack-Pi Arabidopsis. Elimination of the AtPAP17 and AtPAP26 functions, in fact, positively influences the expression and activity of other APases-particularly AtPAP26 in atpap17 mutant and AtPAP17 in atpap26 mutant (Rouached et al., 2010; Farhadi et al., 2020) and/or Pi transporters. In other words, this confirms the recovery and compensation roles of AtPAP17 and AtPAP26 under phosphate deficient conditions.

Our results showed that knockout mutation of AtPAP17 or AtPAP26 genes led extremely to sense the phosphorus imbalance in Mu17, Mu26, and DM plants imposed to salinity and even normal conditions $(0 \mathrm{mM} \mathrm{NaCl})$ compared to wild-type and $\mathrm{OE}$ lines at the same condition. It seems that phosphate homeostasis in cells of mutant plants was also disturbed at normal condition $(0 \mathrm{mM} \mathrm{NaCl})$ since the functions of these genes can be attributed to the dual role of the main components of the compensatory network (Hurley et al., 2010; Farhadi et al., 2020). In other words, the activity of the compensatory network in response to these two genes' destruction could not entirely compensate the intercellular Pi homeostasis at normal condition. Several studies have also indicated that the absence of AtPAP12, AtPAP17, and AtPAP26 was compensated by upregulation of other PSI PAP isozymes (Tran et al., 2010b; Robinson et al., 2012; Farhadi et al., 2020). However, when the functions of AtPAP17 and AtPAP26 were eliminated in the Mu17, Mu26, and DM plants, their functions could not be fully compensated by other PSI PAP isozymes at 100 and $150 \mathrm{mM} \mathrm{NaCl}$, which led to a more severe phosphate deficiency (Table 4).

To sum up, our results showed that nonspecific APases most likely had compensation roles in mutant plants to enhance Pi releasing, recycling, and scavenging from both internal and external resources. However, with increasing $\mathrm{NaCl}$ concentration from 50 to 100 and $150 \mathrm{mM}$, these compensation roles were not showed in mutant plants (Table 4).

These results indicated that apparently both PAP17 and PAP26 genes are involved in plant response to salt tolerance by controlling various downstream biological pathways. The stimulus of these both genes could be derived from the critical roles of their APase activity and non-APase activity, such as alkaline peroxidase activity (Figure 7). This conclusion was supported by comparing the PAP17 expression level in OE17 shoots and roots, and the PAP26 level expression in OE26 shoots and roots at 0 and $150 \mathrm{mM} \mathrm{NaCl}$. It is herewith suggested that the non-APase activity role of these two is confirmed by the increased expression in PAP17 and PAP26 in OE17 and OE17 genotypes at high salinity, respectively, since there were adequate levels of the gene expression for Pi homeostasis.

\section{CONCLUSION}

Overall, to our knowledge, this study is the first report describing the effects of AtPAP17 and AtPAP26 genes in salt stress conditions. This could open a new insight of salt tolerance in A. thaliana with improvement in various aspects of the molecular, biochemical, physiological, and morphological mechanisms. The results clearly pointed out that AtPAP17 and AtPAP26 proteins are responsible as two novel regulators engaged in salt tolerance. It is also highlighted the fact that AtPAP17 and AtPAP26 genes would enable plants to activate the numerous biochemical 
pathways toward adaptive responses to high-stress salt. This could be such a direct and/or indirect influence that minimizes the deleterious effects of the stress. Providing such a novel practical and approach to boost salt tolerance is the main point that distinguishes this study from previous ones. In fact, the genetic modification of such genes that motivate a group of genes involved in salt tolerance might be the most appropriate strategy for salt tolerance since many genes determine plant adaptation. Consequently, we suggest AtPAP17 and AtPAP26 genes, as two candidate genes, for molecular breeding of salt-tolerance enhancement in crop plants.

\section{DATA AVAILABILITY STATEMENT}

The original contributions presented in the study are included in the article/supplementary material, further inquiries can be directed to the corresponding author/s.

\section{REFERENCES}

Abel, S., Ticconi, C. A., and Delatorre, C. A. (2002). Phosphate sensing in higher plants. Physiol. Plant. 115, 1-8.

Aebi, H. (1974). Catalases. Methods Enzym. Anal. 2, 673-684.

Ahanger, M. A., and Agarwal, R. (2017). Salinity stress induced alterations in antioxidant metabolism and nitrogen assimilation in wheat (Triticum aestivum L) as influenced by potassium supplementation. Plant Physiol. Biochem. 115, 449-460. doi: 10.1016/j.plaphy.2017.04.017

Ahanger, M. A., Aziz, U., Alsahli, A. A., Alyemeni, M. N., and Ahmad, P. (2020). Influence of exogenous salicylic acid and nitric oxide on growth, photosynthesis, and ascorbate-glutathione cycle in salt stressed Vigna angularis. Biomolecules 10:42. doi: 10.3390/biom 10010042

Ahmad, P., Abass Ahanger, M., Nasser Alyemeni, M., Wijaya, L., Alam, P., and Ashraf, M. (2018a). Mitigation of sodium chloride toxicity in Solanum lycopersicum L. by supplementation of jasmonic acid and nitric oxide. J. Plant Interact. 13, 64-72. doi: 10.1080/17429145.2017.1420830

Ahmad, P., Alyemeni, M., Ahanger, M., Egamberdieva, D., Wijaya, L., and Alam, P. (2018b). Salicylic acid (SA) induced alterations in growth, biochemical attributes and antioxidant enzyme activity in faba bean (Vicia faba L.) seedlings under $\mathrm{NaCl}$ toxicity. Russ. J. Plant Physiol. 65, 104-114. doi: 10.1134/ s1021443718010132

Ahmad, R., Hussain, S., Anjum, M. A., Khalid, M. F., Saqib, M., Zakir, I., et al. (2019). "Oxidative stress and antioxidant defense mechanisms in plants under salt stress," in Plant Abiotic Stress Tolerance, eds S. Hasanuzzaman, K. R. Hakeem, K. Nahar, and H. F. Alharby, (Cham: Springer), 191-205. doi: 10.1007/ 978-3-030-06118-0_8

Alexieva, V., Sergiev, I., Mapelli, S., and Karanov, E. (2001). The effect of drought and ultraviolet radiation on growth and stress markers in pea and wheat. Plant Cell Environ. 24, 1337-1344. doi: 10.1046/j.1365-3040.2001.00778.x

Ali, A., Maggio, A., Bressan, R. A., and Yun, D.-J. (2019). Role and functional differences of HKT1-type transporters in plants under salt stress. Int. J. Mol. Sci. 20:1059. doi: 10.3390/ijms20051059

Ames, B. N. (1966). Assay of inorganic phosphate, total phosphate and phosphatase. Methods Enzymol. 8, 115-118. doi: 10.1016/0076-6879(66)08 014-5

Annunziata, M. G., Ciarmiello, L. F., Woodrow, P., Maximova, E., Fuggi, A., and Carillo, P. (2017). Durum wheat roots adapt to salinity remodeling the cellular content of nitrogen metabolites and sucrose. Front. Plant Sci. 7:2035. doi: $10.3389 /$ fpls.2016.02035

Arnon, A. (1967). Method of extraction of chlorophyll in the plants. Agron. J. 23, $112-121$.

\section{AUTHOR CONTRIBUTIONS}

MA-V performed all the experiments and data analysis, and wrote the manuscript. MS supervised the project and provided editorial input into the writing. GK advised the project. All authors contributed to the article and approved the submitted version.

\section{ACKNOWLEDGMENTS}

The authors gratefully acknowledge the support provided for this project by the Tarbiat Modares University (TMU) and National Institute of Genetic Engineering and Biotechnology (NIGEB). The authors thank Farhad Ghavami and Petronia Carillo (Department of Environmental Biological and Pharmaceutical Sciences and Technologies, Università degli Studi della Campania "Luigi Vanvitelli" Caserta, Italy) for their valuable comments and serving as editor on the manuscript revision.

Bargaz, A., Nassar, R., Rady, M., Gaballah, M., Thompson, S., Brestic, M., et al. (2016). Improved salinity tolerance by phosphorus fertilizer in two Phaseolus vulgaris recombinant inbred lines contrasting in their P-efficiency. J. Agron. Crop Sci. 202, 497-507. doi: 10.1111/jac.12181

Bartels, D., and Sunkar, R. (2005). Drought and salt tolerance in plants. Crit. Rev. Plant Sci. 24, 23-58.

Bates, L., Waldren, R., and Teare, I. (1973). Rapid determination of free proline for water-stress studies. Plant Soil 39, 205-207. doi: 10.1007/bf00018060

Bradford, M. M. (1976). A rapid and sensitive method for the quantitation of microgram quantities of protein utilizing the principle of protein-dye binding. Anal. Biochem. 72, 248-254. doi: 10.1016/0003-2697(76)90527-3

Brown, C., Pezeshki, S., and DeLaune, R. (2006). The effects of salinity and soil drying on nutrient uptake and growth of Spartina alterniflora in a simulated tidal system. Environ. Exp. Bot. 58, 140-148. doi: 10.1016/j.envexpbot.2005. 07.006

Carstensen, A., Herdean, A., Schmidt, S. B., Sharma, A., Spetea, C., Pribil, M., et al. (2018). The impacts of phosphorus deficiency on the photosynthetic electron transport chain. Plant Physiol. 177, 271-284. doi: 10.1104/pp.17.01624

Chaves, M. M., Flexas, J., and Pinheiro, C. (2009). Photosynthesis under drought and salt stress: regulation mechanisms from whole plant to cell. Ann. Bot. 103, 551-560. doi: 10.1093/aob/mcn125

Chinnusamy, V., Zhu, J., and Zhu, J.-K. (2006). "Salt stress signaling and mechanisms of plant salt tolerance," in Genetic Engineering, ed. J. K. Setlow, (Boston, MA: Springer), 141-177. doi: 10.1007/0-387-25856-6_9

Deinlein, U., Stephan, A. B., Horie, T., Luo, W., Xu, G., and Schroeder, J. I. (2014). Plant salt-tolerance mechanisms. Trends Plant Sci. 19, 371-379.

Del Pozo, J. C., Allona, I., Rubio, V., Leyva, A., De La Peña, A., Aragoncillo, C., et al. (1999). A type 5 acid phosphatase gene from Arabidopsis thaliana is induced by phosphate starvation and by some other types of phosphate mobilising/oxidative stress conditions. Plant J. 19, 579-589. doi: 10.1046/j. 1365-313X.1999.00562.x

DeLong, A. (2006). Switching the flip: protein phosphatase roles in signaling pathways. Curr. Opin. Plant Biol. 9, 470-477. doi: 10.1016/j.pbi.2006.07.015

Duff, S. M., Sarath, G., and Plaxton, W. C. (1994). The role of acid phosphatases in plant phosphorus metabolism. Physiol. Plant. 90, 791-800. doi: 10.1111/j.13993054.1994.tb02539.x

Elwan, M. W. (2010). Ameliorative effects of di-potassium hydrogen orthophosphate on salt-stressed eggplant. J. Plant Nutr. 33, 1593-1604. doi: 10.1080/01904167.2010.496884

Farhadi, S., Sabet, M. S., Malboobi, M. A., and Moieni, A. (2020). The critical role of AtPAP17 and AtPAP26 genes in Arabidopsis phosphate compensation network. Front. Plant Sci. 11:565865. doi: 10.3389/fpls.2020.565865 
Gaxiola, R., Li, J., Undurraga, S., Dang, L. M., Allen, G. J., Alper, S. L., et al. (2001). Drought- and salt-tolerant plants result from overexpression of the AVP1H ${ }^{+}$-pump. Proc. Natl. Acad. Sci. U.S.A. 98, 11444-11449. doi: 10.1073/ pnas. 191389398

Goldstein, A. H., Baertlein, D. A., and McDaniel, R. G. (1988). Phosphate starvation inducible metabolism in Lycopersicon esculentum I. excretion of acid phosphatase by tomato plants and suspension-cultured cells. Plant Physiol. 87, 711-715. doi: 10.1104/pp.87.3.711

Grieve, C., and Grattan, S. (1983). Rapid assay for determination of water soluble quaternary ammonium compounds. Plant Soil 70, 303-307. doi: 10.1007/ bf02374789

Hamada, A., and El-Enany, A. (1994). Effect of $\mathrm{NaCl}$ salinity on growth, pigment and mineral element contents, and gas exchange of broad bean and pea plants. Biol. Plant. 36, 75-81. doi: 10.1007/bf02921273

Hammond, J. P., and White, P. J. (2008). Sucrose transport in the phloem: integrating root responses to phosphorus starvation. J. Exp. Bot. 59, 93-109. doi: $10.1093 / \mathrm{jxb} / \mathrm{erm} 221$

Hanin, M., Ebel, C., Ngom, M., Laplaze, L., and Masmoudi, K. (2016). New insights on plant salt tolerance mechanisms and their potential use for breeding. Front. Plant Sci. 7:1787. doi: 10.3389/fpls.2016.01787

Hasegawa, P. M. (2013). Sodium $\left(\mathrm{Na}^{+}\right)$homeostasis and salt tolerance of plants. Environ. Exp. Bot. 92, 19-31. doi: 10.1016/j.envexpbot.2013. 03.001

Hatam, Z., Sabet, M. S., Malakouti, M. J., and Homaee, M. (2019). A quantitative approach for fertilizer recommendation under saline conditions. Arch. Agron. Soil Sci. 66, 502-516. doi: 10.1080/03650340.2019.1624725

Hatam, Z., Sabet, M. S., Malakouti, M. J., Mokhtassi-Bidgoli, A., and Homaee, M. (2020). Zinc and potassium fertilizer recommendation for cotton seedlings under salinity stress based on gas exchange and chlorophyll fluorescence responses. S. Afr. J. Bot. 130, 155-164. doi: 10.1016/j.sajb.2019.11.032

Hodges, D. M., DeLong, J. M., Forney, C. F., and Prange, R. K. (1999). Improving the thiobarbituric acid-reactive-substances assay for estimating lipid peroxidation in plant tissues containing anthocyanin and other interfering compounds. Planta 207, 604-611. doi: 10.1007/s004250050524

Hur, Y. J., Lee, H. G., Jeon, E. J., Lee, Y. Y., Nam, M. H., Yi, G., et al. (2007). A phosphate starvation-induced acid phosphatase from Oryza sativa: phosphate regulation and transgenic expression. Biotechnol. Lett. 29, 829-835. doi: 10. 1007/s10529-007-9318-5

Hurley, B. A., Tran, H. T., Marty, N. J., Park, J., Snedden, W. A., Mullen, R. T., et al. (2010). The dual-targeted purple acid phosphatase isozyme AtPAP26 is essential for efficient acclimation of Arabidopsis to nutritional phosphate deprivation. Plant Physiol. 153, 1112-1122. doi: 10.1104/pp.110.153270

Isayenkov, S. V., and Maathuis, F. J. (2019). Plant salinity stress: many unanswered questions remain. Front. Plant Sci. 10:80. doi: 10.3389/fpls.2019.00080

Ji, H., Pardo, J. M., Batelli, G., Van Oosten, M. J., Bressan, R. A., and Li, X. (2013). The salt overly sensitive (SOS) pathway: established and emerging roles. Mol. Plant 6, 275-286. doi: 10.1093/mp/sst017

Katiyar-Agarwal, S., Zhu, J., Kim, K., Agarwal, M., Fu, X., Huang, A., et al. (2006). The plasma membrane $\mathrm{Na}+\mathrm{H}+$ antiporter SOS1 interacts with RCD1 and functions in oxidative stress tolerance in Arabidopsis. Proc. Natl. Acad. Sci. U.S.A. 103, 18816-18821. doi: 10.1073/pnas.0604711103

Kaya, C., Higgs, D., and Kirnak, H. (2001). The effects of high salinity $(\mathrm{NaCl})$ and supplementary phosphorus and potassium on physiology and nutrition development of spinach. Bulg. J. Plant Physiol. 27, 47-59.

Krizek, D. T., Britz, S. J., and Mirecki, R. M. (1998). Inhibitory effects of ambient levels of solar UV-A and UV-B radiation on growth of cv. New Red Fire lettuce. Physiol. Plant. 103, 1-7. doi: 10.1034/j.1399-3054.1998.1030101.x

Lee, S. C., Lan, W., Buchanan, B. B., and Luan, S. (2009). A protein kinasephosphatase pair interacts with an ion channel to regulate ABA signaling in plant guard cells. Proc. Natl. Acad. Sci. U.S.A. 106, 21419-21424. doi: 10.1073/ pnas.0910601106

Lehmann, S., Funck, D., Szabados, L., and Rentsch, D. (2010). Proline metabolism and transport in plant development. Amino Acids 39, 949-962. doi: 10.1007/ s00726-010-0525-3

Liang, M., Lin, M., Lin, Z., Zhao, L., Zhao, G., Li, Q., et al. (2015). Identification, functional characterization, and expression pattern of a $\mathrm{NaCl}$-inducible vacuolar $\mathrm{Na}+/ \mathrm{H}+$ antiporter in chicory (Cichorium intybus L.). Plant Growth Regul. 75, 605-614. doi: 10.1007/s10725-014-9963-3
Liao, H., Wong, F.-L., Phang, T.-H., Cheung, M.-Y., Li, W.-Y. F., Shao, G., et al. (2003). GmPAP3, a novel purple acid phosphatase-like gene in soybean induced by $\mathrm{NaCl}$ stress but not phosphorus deficiency. Gene 318, 103-111. doi: 10.1016/ s0378-1119(03)00764-9

Lohrasebi, T., Malboobi, M. A., Samaeian, A., and Sanei, V. (2007). Differential expression of Arabidopsis thaliana acid phosphatases in response to abiotic stresses. Iran. J. Biotechnol. 5, 130-139.

Luan, S. (1998). Protein phosphatases and signaling cascades in higher plants. Trends Plant Sci. 3, 271-275. doi: 10.1016/s1360-1385(98)01258-8

Luan, S. (2003). Protein phosphatases in plants. Annu. Rev. Plant Biol. 54, 63-92.

Ma, X.-F., Wright, E., Ge, Y., Bell, J., Xi, Y., Bouton, J. H., et al. (2009). Improving phosphorus acquisition of white clover (Trifolium repens L.) by transgenic expression of plant-derived phytase and acid phosphatase genes. Plant Sci. 176, 479-488. doi: 10.1016/j.plantsci.2009.01.001

Machado, R. M. A., and Serralheiro, R. P. (2017). Soil salinity: effect on vegetable crop growth. Management practices to prevent and mitigate soil salinization. Horticulturae 3:30. doi: 10.3390/horticulturae3020030

Maeshima, M. (2000). Vacuolar H+-pyrophosphatase. Biochim. Biophys. Acta 1465, $37-51$.

Malhotra, H., Sharma, S., and Pandey, R. (2018). "Phosphorus nutrition: plant growth in response to deficiency and excess," in Plant Nutrients and Abiotic Stress Tolerance, eds M. Hasanuzzaman, M. Fujita, H. Oku, K. Nahar, and B. Hawrylak-Nowak, (Singapore: Springer), 171-190. doi: 10.1007/978-981-109044-8_7

Malik, C. P., and Singh, M. (1980). Plant Enzymology and Histo-Enzymology. New Delhi: Kalyani Publishers.

Martinez, V., and Lächli, A. (1991). Phosphorus translocation in salt-stressed cotton. Physiol. Plant. 83, 627-632. doi: 10.1034/j.1399-3054.1991.830415.x

Martinez, V., and Läuchli, A. (1994). Salt-induced inhibition of phosphate uptake in plants of cotton (Gossypium hirsutum L.). New Phytol. 126, 609-614. doi: 10.1111/j.1469-8137.1994.tb02955.x

Meena, M., Divyanshu, K., Kumar, S., Swapnil, P., Zehra, A., Shukla, V., et al. (2019). Regulation of L-proline biosynthesis, signal transduction, transport, accumulation and its vital role in plants during variable environmental conditions. Heliyon 5:e02952. doi: 10.1016/j.heliyon.2019.e02952

Munns, R., and Gilliham, M. (2015). Salinity tolerance of crops-what is the cost? New Phytol. 208, 668-673. doi: 10.1111/nph.13519

Munns, R., and Tester, M. (2008). Mechanisms of salinity tolerance. Annu. Rev. Plant Biol. 59, 651-681. doi: 10.1146/annurev.arplant.59.032607.092911

Nakano, Y., and Asada, K. (1981). Hydrogen peroxide is scavenged by ascorbatespecific peroxidase in spinach chloroplasts. Plant Cell Physiol. 22, 867-880.

Naseri, J. I., Truong, N. T., Hörentrup, J., Kuballa, P., Vogel, A., Rompel, A., et al. (2004). Porcine purple acid phosphatase: heterologous expression, characterization, and proteolytic analysis. Arch. Biochem. Biophys. 432, 25-36. doi: 10.1016/j.abb.2004.08.008

Navarro, J. M., Botella, M. A., Cerdá, A., and Martinez, V. (2001). Phosphorus uptake and translocation in salt-stressed melon plants. J. Plant Physiol. 158, 375-381. doi: 10.1078/0176-1617-00147

Pardo, J. M., Reddy, M. P., Yang, S., Maggio, A., Huh, G.-H., Matsumoto, T., et al. (1998). Stress signaling through $\mathrm{Ca}_{2}{ }^{+} /$calmodulin-dependent protein phosphatase calcineurin mediates salt adaptation in plants. Proc. Natl. Acad. Sci. U.S.A. 95, 9681-9686. doi: 10.1073/pnas.95.16.9681

Parida, A. K., and Das, A. B. (2005). Salt tolerance and salinity effects on plants: a review. Ecotoxicol. Environ. Saf. 60, 324-349. doi: 10.1016/j.ecoenv.2004.06.010

Parihar, P., Singh, S., Singh, R., Singh, V. P., and Prasad, S. M. (2015). Effect of salinity stress on plants and its tolerance strategies: a review. Environ. Sci. Pollut. Res. 22, 4056-4075. doi: 10.1007/s11356-014-3739-1

Park, H. J., Kim, W.-Y., and Yun, D.-J. (2016). A new insight of salt stress signaling in plant. Mol. Cells 39, 447-459. doi: 10.14348/molcells.2016.0083

Plaxton, W. C. (2004). "Plant response to stress: biochemical adaptations to phosphate deficiency," Encyclopedia of Plant and Crop Science, ed. R. Goodman, (New York, NY: Marcel Dekker), 976-980. doi: 10.1081/e-epcs- 120010648

Plaxton, W. C., and Carswell, M. C. (1999). "Metabolic aspects of the phosphate starvation response in plants," Plant Responses to Environmental Stresses: From Phytohormones to Genome Reorganization, ed. H. R. Lerner, (New York, NY: Marcel Dekker), 349-372. doi: 10.1201/9780203743157-16

Plaxton, W. C., and Tran, H. T. (2011). Metabolic adaptations of phosphate-starved plants. Plant Physiol. 156, 1006-1015. doi: 10.1104/pp.111.175281 
Qin, C., Ahanger, M. A., Lin, B., Huang, Z., Zhou, J., Ahmed, N., et al. (2020). Comparative transcriptome analysis reveals the regulatory effects of acetylcholine on salt tolerance of Nicotiana benthamiana. Phytochemistry 181:112582. doi: 10.1016/j.phytochem.2020.112582

Rahikainen, M., Pascual, J., Alegre, S., Durian, G., and Kangasjärvi, S. (2016). PP2A phosphatase as a regulator of ROS signaling in plants. Antioxidants 5:8. doi: $10.3390 /$ antiox 5010008

Robinson, W. D., Park, J., Tran, H. T., Del Vecchio, H. A., Ying, S., Zins, J. L., et al. (2012). The secreted purple acid phosphatase isozymes AtPAP12 and AtPAP26 play a pivotal role in extracellular phosphate-scavenging by Arabidopsis thaliana. J. Exp. Bot. 63, 6531-6542. doi: 10.1093/jxb/ers309

Rouached, H., Arpat, A. B., and Poirier, Y. (2010). Regulation of phosphate starvation responses in plants: signaling players and cross-talks. Mol. Plant 3, 288-299. doi: $10.1093 / \mathrm{mp} / \mathrm{ssp} 120$

Rychter, A.M., and Rao, I. M. (2005). "Role of phosphorus in photosynthetic carbon metabolism," in Handbook of Photosynthesis, 2nd Edn, ed. Pessarakli, M. (Boca Raton: Taylor \& Francis Group), 123-148.

Sabet, M. S., Zamani, K., Lohrasebi, T., Malboobi, M. A., and Valizadeh, M. (2018). Functional assessment of an overexpressed Arabidopsis purple acid phosphatase gene (AtPAP26) in tobacco plants. Iran. J. Biotechnol. 16:e2024.

Schweighofer, A., Hirt, H., and Meskiene, I. (2004). Plant PP2C phosphatases: emerging functions in stress signaling. Trends Plant Sci. 9, 236-243. doi: 10. 1016/j.tplants.2004.03.007

Shahriaripour, R., Tajabadi Pour, A., and Mozaffari, V. (2011). Effects of salinity and soil phosphorus application on growth and chemical composition of pistachio seedlings. Commun. Soil Sci. Plant Anal. 42, 144-158. doi: 10.1080/00103624. 2011.535065

Sheligl, H. (1986). Die verwertung orgngischer souren durch chlorella lincht. Planta J. 47:51.

Shi, H., Ishitani, M., Kim, C., and Zhu, J. K. (2000). The Arabidopsis thaliana salt tolerance gene SOS1 encodes a putative $\mathrm{Na}^{+} / \mathrm{H}^{+}$antiporter. Proc. Natl. Acad. Sci. U.S.A. 97, 6896-6901. doi: 10.1073/pnas.1201 70197

Singh, A., Giri, J., Kapoor, S., Tyagi, A. K., and Pandey, G. K. (2010). Protein phosphatase complement in rice: genome-wide identification and transcriptional analysis under abiotic stress conditions and reproductive development. BMC Genomics 11:435. doi: 10.1186/1471-2164$11-435$

Sopory, S. K., and Munshi, M. (1998). Protein kinases and phosphatases and their role in cellular signaling in plants. Crit. Rev. Plant Sci. 17, 245-318. doi: 10.1080/07352689891304230

Tester, M., and Davenport, R. (2003). $\mathrm{Na}^{+}$tolerance and $\mathrm{Na}^{+}$transport in higher plants. Ann. Bot. 91, 503-527. doi: 10.1093/aob/mcg058

Tran, H. T., Hurley, B. A., and Plaxton, W. C. (2010a). Feeding hungry plants: the role of purple acid phosphatases in phosphate nutrition. Plant Sci. 179, 14-27. doi: 10.1016/j.plantsci.2010.04.005

Tran, H. T., Qian, W., Hurley, B. A., She, Y. M., Wang, D., and Plaxton, W. C. (2010b). Biochemical and molecular characterization of AtPAP12 and AtPAP26: the predominant purple acid phosphatase isozymes secreted by phosphate-starved Arabidopsis thaliana. Plant Cell Environ. 33, 1789-1803. doi: 10.1111/j.1365-3040.2010.02184.x

Veljanovski, V., Vanderbeld, B., Knowles, V. L., Snedden, W. A., and Plaxton, W. C. (2006). Biochemical and molecular characterization of AtPAP26, a vacuolar purple acid phosphatase up-regulated in phosphate-deprived Arabidopsis suspension cells and seedlings. Plant Physiol. 142, 1282-1293. doi: 10.1104/pp. 106.087171

Wang, L., Li, Z., Qian, W., Guo, W., Gao, X., Huang, L., et al. (2011). The Arabidopsis purple acid phosphatase AtPAP10 is predominantly associated with the root surface and plays an important role in plant tolerance to phosphate limitation. Plant Physiol. 157, 1283-1299. doi: 10.1104/pp.111.183723

Wang, L., Lu, S., Zhang, Y., Li, Z., Du, X., and Liu, D. (2014). Comparative genetic analysis of Arabidopsis purple acid phosphatases AtPAP10, AtPAP12, and AtPAP26 provides new insights into their roles in plant adaptation to phosphate deprivation. J. Integr. Plant Biol. 56, 299-314. doi: 10.1111/jipb.12184

Wang, X., Wang, Y., Tian, J., Lim, B. L., Yan, X., and Liao, H. (2009). Overexpressing AtPAP15 enhances phosphorus efficiency in soybean. Plant Physiol. 151, 233-240. doi: 10.1104/pp.109.138891

Woodrow, P., Ciarmiello, L. F., Annunziata, M. G., Pacifico, S., Iannuzzi, F., Mirto, A., et al. (2017). Durum wheat seedling responses to simultaneous high light and salinity involve a fine reconfiguration of amino acids and carbohydrate metabolism. Physiol. Plant. 159, 290-312. doi: 10.1111/ppl.12513

Xiao, K., Katagi, H., Harrison, M., and Wang, Z.-Y. (2006). Improved phosphorus acquisition and biomass production in Arabidopsis by transgenic expression of a purple acid phosphatase gene from M. truncatula. Plant Sci. 170, 191-202. doi: 10.1016/j.plantsci.2005.08.001

Xu, C., Zheng, L., Gao, C., Wang, C., Liu, G., Jiang, J., et al. (2011). Ovexpression of a vacuolar $\mathrm{H}+$-ATPase $\mathrm{c}$ subunit gene mediates physiological changes leading to enhanced salt tolerance in transgenic tobacco. Plant Mol. Biol. Report. 29, 424-430. doi: 10.1007/s11105-010-0247-4

Yamaguchi, T., and Blumwald, E. (2005). Developing salt-tolerant crop plants: challenges and opportunities. Trends Plant Sci. 10, 615-620. doi: 10.1016/j. tplants.2005.10.002

Yokoi, S., Quintero, F. J., Cubero, B., Ruiz, M. T., Bressan, R. A., Hasegawa, P. M., et al. (2002). Differential expression and function of Arabidopsis thaliana NHX Na+/H+ antiporters in the salt stress response. Plant J. 30, 529-539. doi: 10.1046/j.1365-313x.2002.01309.x

Yuan, H., and Liu, D. (2008). Signaling components involved in plant responses to phosphate starvation. J. Integr. Plant Biol. 50, 849-859. doi: 10.1111/j.17447909.2008.00709.x

Zamani, K., Sabet, M., Lohrasebi, T., Mousavi, A., and Malboobi, M. (2012). Improved phosphate metabolism and biomass production by overexpression of AtPAP18 in tobacco. Biologia 67, 713-720.

Zhao, C., Zhang, H., Song, C., Zhu, J.-K., and Shabala, S. (2020). Mechanisms of plant responses and adaptation to soil salinity. Innovation 1:100017. doi: 10.1016/j.xinn.2020.100017

Zörb, C., Geilfus, C. M., and Dietz, K. J. (2019). Salinity and crop yield. Plant Biol. 21, 31-38. doi: 10.1111/plb.12884

Conflict of Interest: The authors declare that the research was conducted in the absence of any commercial or financial relationships that could be construed as a potential conflict of interest.

Copyright (c) 2021 Abbasi-Vineh, Sabet and Karimzadeh. This is an open-access article distributed under the terms of the Creative Commons Attribution License (CC BY). The use, distribution or reproduction in other forums is permitted, provided the original author(s) and the copyright owner(s) are credited and that the original publication in this journal is cited, in accordance with accepted academic practice. No use, distribution or reproduction is permitted which does not comply with these terms. 